\title{
Advances in synthetic lethality for cancer therapy: cellular mechanism and clinical translation
}

Win Topatana ${ }^{1,2+}$, Sarun Juengpanich ${ }^{1,2+}$, Shijie $\mathrm{Li}^{1+}$, Jiasheng Cao ${ }^{1}$, Jiahao Hu${ }^{1}$, Jiyoung Lee $^{3}$, Kenneth Suliyanto ${ }^{2}$, Diana Ma ${ }^{2}$, Bin Zhang ${ }^{1}$, Mingyu Chen ${ }^{1,2^{*}}$ and Xiujun Cai ${ }^{1,2,4^{*}}$

\begin{abstract}
Synthetic lethality is a lethal phenomenon in which the occurrence of a single genetic event is tolerable for cell survival, whereas the co-occurrence of multiple genetic events results in cell death. The main obstacle for synthetic lethality lies in the tumor biology heterogeneity and complexity, the inadequate understanding of synthetic lethal interactions, drug resistance, and the challenges regarding screening and clinical translation. Recently, DNA damage response inhibitors are being tested in various trials with promising results. This review will describe the current challenges, development, and opportunities for synthetic lethality in cancer therapy. The characterization of potential synthetic lethal interactions and novel technologies to develop a more effective targeted drug for cancer patients will be explored. Furthermore, this review will discuss the clinical development and drug resistance mechanisms of synthetic lethality in cancer therapy. The ultimate goal of this review is to guide clinicians at selecting patients that will receive the maximum benefits of DNA damage response inhibitors for cancer therapy.
\end{abstract}

Keywords: Cancer therapy, Synthetic lethality, PARP inhibitors, DNA damage response inhibitors, DNA repair

\section{Introduction}

Cancer is regarded as a complex disease with multiple genetic changes, including oncogenes, tumor suppressors, DNA repair, cancer metabolism, and genetic background, which results in excessive growth, metastasis, and drug resistance [1-3]. The advances in genome sequencing over the past decade demonstrated that tumor-specific genetic alterations and biological changes drive tumor progression, which leads to susceptibilities that could be manipulated to target tumors selectively [4]. Multiple studies have indicated that synthetic lethality is a promising approach that could improve cancer

\footnotetext{
* Correspondence: mychen@zju.edu.cn; srrsh_cxj@zju.edu.cn

tWin Topatana, Sarun Juengpanich and Shijie Li contributed equally to this work.

${ }^{1}$ Department of General Surgery, Sir Run-Run Shaw Hospital, Zhejiang University, Hangzhou 310016, China

Full list of author information is available at the end of the article
}

research and treatment $[5,6]$. The concept of synthetic lethality originates from genetic studies in fruit flies which describes the incompatibility between pairs of alleles [7] and indicates the instance where the cooccurrence of multiple gene mutations results in cell death [8]. Unlike conventional targeted therapies, synthetic lethal therapies promote mutation indirect targeting by identifying an alternative synthetic lethal target, ranging from oncogenes to tumor suppressors, DNA repair, cancer metabolism, and even genetic background [9]. Therefore, synthetic lethal interactions have the potential to broaden the strategies of anticancer treatments and stimulate drug discovery.

Synthetic lethal therapy has been referred to as one of the most effective cancer therapies in the last decade. Poly(ADP-ribose) polymerase (PARP) inhibitors, which targeted the inhibition of particular DNA repair pathways, have become the drug based on the 
synthetic lethal approach that is approved for clinical use to target BRCA1/2-mutated tumors. This synthetic lethal interaction was discovered and approved as a specific and safer therapy for cancer [10, 11]. Various studies demonstrated that PARP inhibitors had promising results in clinical trials for BRCA1/2mutant tumors, such as breast cancer, ovarian cancer, pancreatic cancer, and prostate cancer [12-16]. Moreover, with the development of new experimental and computational approaches, researchers have identified and validated several new synthetic lethal interactions. The underlying synthetic lethal interactions, mechanistic characterization, and screening approaches will raise the possibility of clinical translations and promote novel and effective synthetic lethality strategies.

This review will describe the current understandings of synthetic lethality mechanisms, advances, and challenges. The advantages and limitations of various approaches for discovering additional synthetic lethal interactions will be explored. Furthermore, recent clinical developments for DNA damage response (DDR) inhibitors and their resistance mechanisms will be discussed. Finally, we will examine the new directions and opportunities for synthetic lethality in anticancertargeted therapy.

\section{Synthetic lethal mechanism}

Synthetic lethality is a phenomenon whereby the concurrent disruption of multiple genes results in cell death, while a disruption in an individual gene is compatible with cell survival (Fig. 1) [9]. Based on targeted therapies acting on the different types of genes driving cancers, synthetic lethality is classified into synthetic sickness lethality and synthetic dosage lethality. In addition, conditional synthetic lethality is regarded as a special type of synthetic lethal interaction. The definition and application of each type of synthetic lethality are summarized in Table 1 . There are multiple factors that affect the mechanism of synthetic lethality, including the tumor microenvironment, metabolic pathway, cell cycle control, epigenetic regulation, and the DNA damage response pathway. The major pathways and mechanisms of synthetic lethality are portrayed in Fig. 2.

Researchers have been assessing the potential of microenvironment-linked synthetic lethality by regulating cellular stress levels. Tumor cells generally suffer more from extreme reactive oxygen species (ROS) or oxidative stress levels, when compared with normal cells, and depends on oxidized nucleotides elimination to survive [22]. Oxidative stress in cancer cells is regulated by the stress-induced transcription factor nuclear factor erythroid 2-related factor 2 (NRF2) [23]. It has been reported that triptolide, a potent NRF2 inhibitor that disrupts glutathione

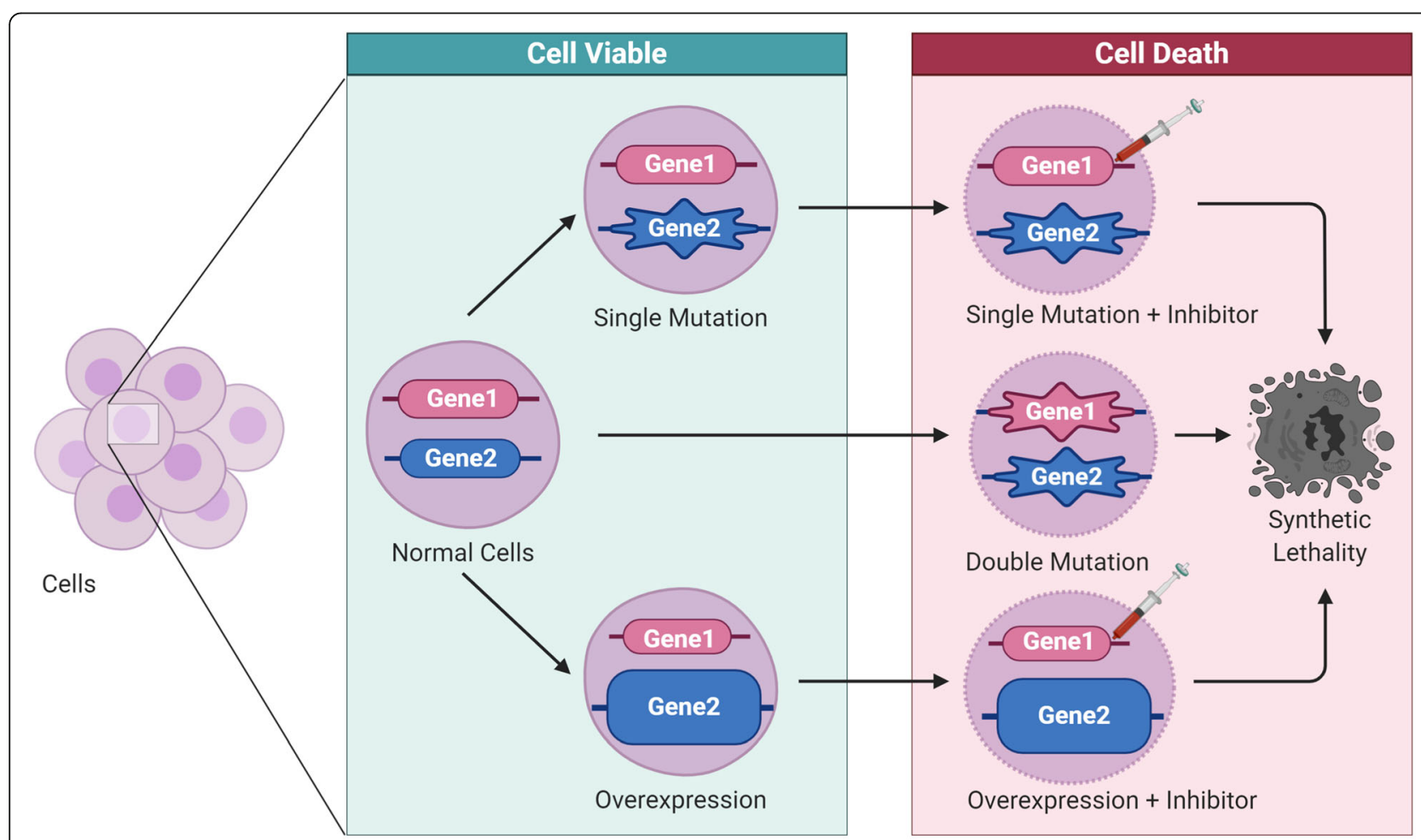

Fig. 1 The principle of synthetic lethality. An individual genetic event is compatible with cell viability (left), whereas the co-occurrence of multiple genetic events causes cell death (right). The star represents a mutation; the large bubble represents genetic overexpression; the syringe represents DNA damage response inhibitor administration 


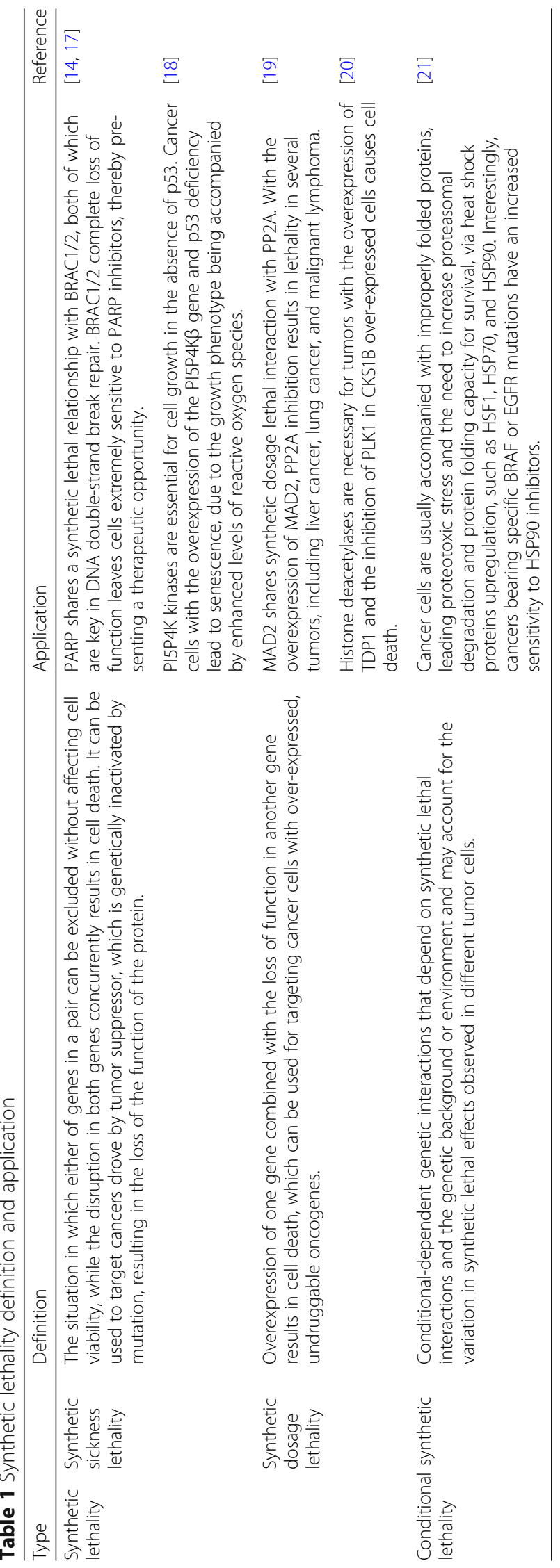




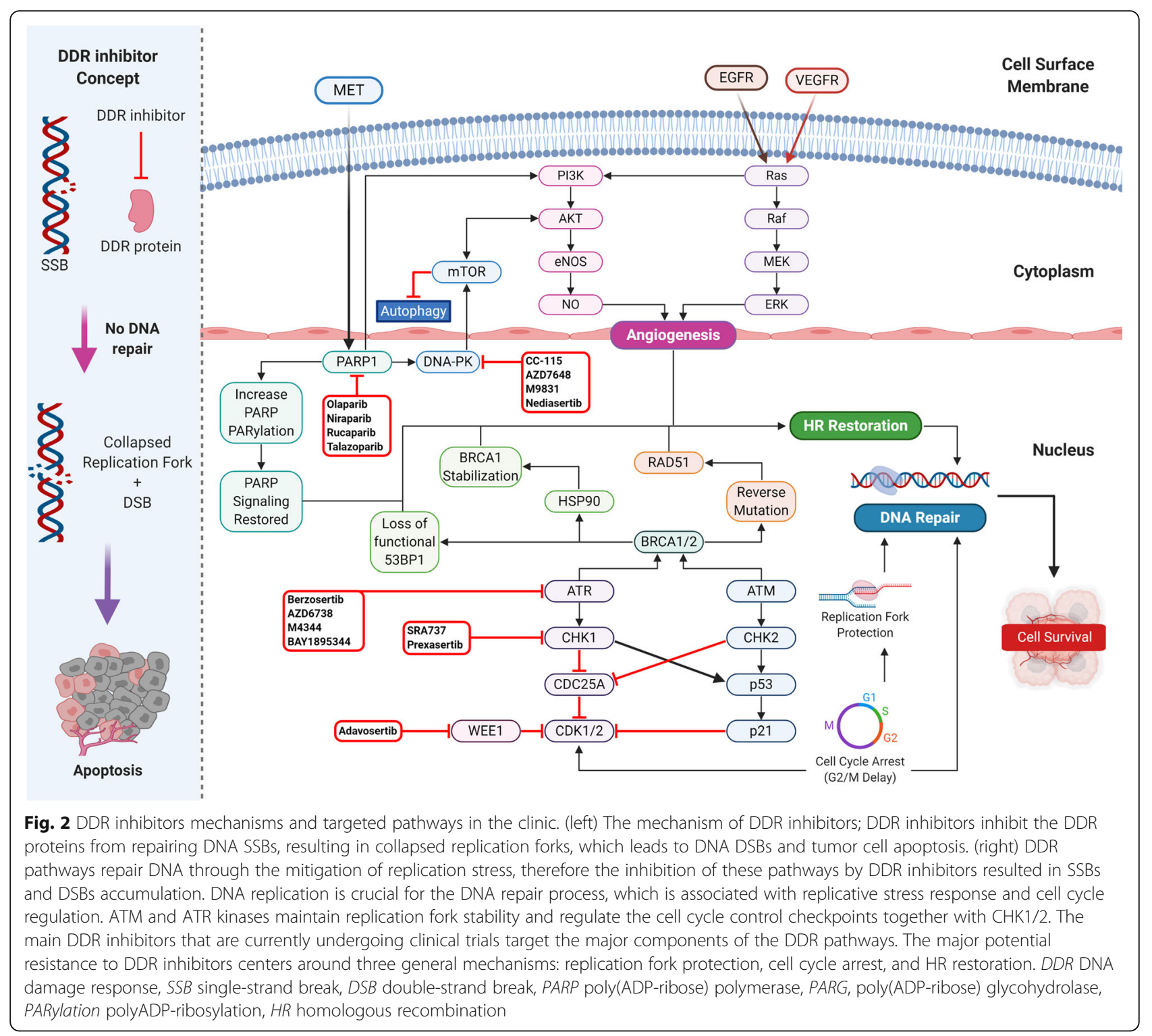

metabolism, have selective cytotoxicity in IDH1-mutated cancer cells [24]. IDH1-mutated cells are dependent on NRF2-guided glutathione synthesis and exhibit increased ROS levels. Therefore, NRF2 inhibition established a synthetic lethal interaction with ROS generated from the mutated IDH1 neomorphic activity. Moreover, proteotoxic stress has been exploited to target tumor cells using synthetic lethality. The combination of heat shock protein 90 (HSP90) and glutaminase inhibitors induces proteotoxic stress and selectively triggers the death of TSC1/2-deficient cells [25]. It has been reported that the major oncogenic pathways have numerous mutated metabolic enzymes [26]. For instance, glycolysis is promoted by RAS or MYC but is inhibited by p53 [27]. AMPK-related kinase 5 shares a synthetic lethal interaction with MYC, as its inhibition leads to ATP reduction and pro-apoptotic response stimulation in cancer cells with MYC overexpression [28]. Thus, metabolism dysregulation is both the cause and the consequence of tumorigenesis [29].

Cell cycle control is a promising method for cancer treatment and synthetic lethality may offer a new direction to inhibit cancer cells directly by specificity utilizing cell cycle control [30]. Synthetic lethal interaction has been observed between $\mathrm{Rb}$ and E2F family transcription factors, both of which regulate cellular proliferation by $\mathrm{G} 1$ checkpoint restriction. Large-scale short hairpin RNA (shRNA) screens demonstrated that $\mathrm{Rb}$-defective tumor cells rely on the E2F transcription factor family such as E2F3 [31]. In addition, gene encoding protein mutations lead to the loss of chromatin remodeling-associated gene function that is common in malignant tumors [32]. Various studies in yeast genetic interaction network demonstrate that a variety of synthetic 
lethal interactions among gene pairs in the DDR pathway prevents harmful DNA damage [5, 33]. Researchers are currently exploring various synthetic lethal interactions in the DDR pathway, which will be discussed later in the review. The identified key genes targeted by synthetic lethality approaches are summarized in Table 2.

Recently, a new strategy using senolytic agents to induce synthetic lethal interactions have shown great promise in cancer treatment. Cancer therapy can induce tumor cell senescence that negatively affects the tumor microenvironment due to the secreted factors, including various growth factors, chemokines, cytokines, and matrix remodeling enzymes [65]. Senescent cells have stable cell cycle arrest with changes in cell chromatin structure, metabolism, and morphology. It has been reported that tumor development can be inhibited by senescence-associated cell cycle arrest. However, various factors secreted from senescent cells can negatively impact the tumor microenvironment by promoting tumor progression or inducing immune-mediated senescent cell clearance [66]. Mice bearing treatment-induced senescence tumors have extended survival after the elimination of senescent cells, whereas mice bearing senescence-resistant tumors do not [67]. It has been demonstrated that the synthetic lethal approach can be used to treat breast and ovarian cancer cells by inducing senescence with PARP inhibitors and senolytic agents. PARP inhibitor-induced senescence leads to the sensitivity of breast and ovarian cancer cells to second-phase synthetic lethal interaction by using senolytic agents to target the senescence state, increasing the combination therapy efficacy in the xenografted breast (MDA-MB231) and ovarian (OV4453, OV1946) cancer models [68]. Senolytic agent treatment combined with PARP inhibitors has proven to be effective in preclinical studies, thus the combination of these synthetic lethal interactions could be further explored to limit drug resistance in the clinics.

\section{Identification of new synthetic lethal interactions}

Due to thousands of mutated genes in various cancers, identifying and validating potential synthetic lethal partner genes in various conditions remain a challenge. The five most common synthetic lethal screening approaches include yeast screens, drug screens, RNA interference (RNAi) screens, clustered regularly interspaced short palindromic repeats (CRISPR) screens, and bioinformatics screens (Fig. 3).

\section{Yeast screens}

Model organisms, such as yeast, were used as initial screens to identify synthetic lethality-based anticancer therapeutic targets [69]. Large-scale development of genetic interaction quantification and double mutants is facilitated by high-throughput yeast mating strategies, such as diploid-based synthetic lethality analysis with microarrays and synthetic genetic array [70, 71]. Costanzo et al. [33] generated a comprehensive Saccharomyces cerevisiae genetic interaction network and identified over 500,000 synthetic sickness and synthetic lethal interactions. These genetic interaction profiles allow the assembly of the cell function hierarchical model, including modules that correspond to protein pathways, cellular compartments, and biological processes, and provides a clear context for synthetic lethal genetic networks in cancer cell lines [72]. Even though a high-throughput refinement can greatly improve the efficiency of yeast screens, attempts to map synthetic lethal partner genes onto human orthologues still remains a challenge [73].

\section{Drug screens}

Drug screens determine the synthetic lethal interactions between drugs and genes by utilizing the library of drugs on various cell lines with specific mutations. Minor progress has been made via high-throughput drug screens in several tumors including cyclin-dependent kinase $1 / 2$ (CDK1/2)-, polo-like kinase 1 (PLK1)-, and WEE1mutated cancers. Drug screens are mainly based on both mutation data and high-throughput drug screening data to identify sensitive mutations that may constitute synthetic lethal interactions [74]. Notably, identifying the synthetic lethal interactions through drug screens are reciprocal. Screening drug libraries in cancer with specific mutations and loss-of-function genetic screening of cells treated with selective drugs via RNAi or CRISPR screens can both determine synthetic lethal interactions. In addition, drug dosage also influences the specificity of identifying potential synthetic lethal interactions. If a new gene-drug synthetic lethal interaction is identified, the preclinical validation and clinical trials would be easily performed. However, due to the inadequate target inhibition and possible side effects of the agent, the efficacy and specificity of target drug inhibition are generally lower than genetic knockdown [6].

\section{RNA interference screens}

The development of RNAi screens that can precisely knockdown mRNAs by introducing exogenous small interfering RNA (siRNA) sequences had made genomewide studies in human cells possible [75]. RNAi screens target post-transcriptional genes by promoting precise mRNAs degradation, which can be divided into shorthairpin and short-interfering screens. RNAi screening technology allows the identification of new genes and genetic networks involved in various biological processes, including protein or organelle function and localization, assays related to cell viability and signal transduction, host cells response to pathogens, and drug 
Table $\mathbf{2}$ Identified key genes in synthetic lethality preclinical studies

\begin{tabular}{|c|c|c|c|c|c|c|}
\hline Gene & Chromosome & Cellular process and mechanism & In vitro & In vivo & Cancer type & Reference \\
\hline ARIDIA & $1 p 36.11$ & $\begin{array}{l}\text { Target SWI/SNF complexes, which } \\
\text { regulate chromatin remodeling. } \\
\text { SWI/SNF complexes are involved } \\
\text { in controlling the cell cycle, DNA } \\
\text { replication, and repairing DNA } \\
\text { damage. }\end{array}$ & $\begin{array}{l}\mathrm{H} 1299, \mathrm{H} 2023, \\
\mathrm{H} 2030\end{array}$ & $\begin{array}{l}\text { Smarca4-deficient } \\
\text { genetically engineered mouse }\end{array}$ & Lung cancer & [34] \\
\hline ATM & $11 q 22.3$ & $\begin{array}{l}\text { Activates cell cycle checkpoints; } \\
\text { recognizes damaged DNA and } \\
\text { triggers ATM-mediated DNA } \\
\text { damage response pathway to } \\
\text { repair damaged DNA strands. }\end{array}$ & $\begin{array}{l}\text { KC }(850,6059 \\
8878), \text { AKC }(995 \\
5615,5980,5982)\end{array}$ & AKC, KC, and SCID mouse & $\begin{array}{l}\text { Pancreatic } \\
\text { cancer }\end{array}$ & {$[35]$} \\
\hline ATR & $3 q 23$ & $\begin{array}{l}\text { Cell cycle checkpoint signaling } \\
\text { activation upon DNA stress and } \\
\text { triggers ATR-mediated DNA } \\
\text { damage sensing. }\end{array}$ & $\begin{array}{l}\text { Human-derived } \\
\mathrm{CLL} \text { and Mec1 cell } \\
\text { line }\end{array}$ & Primary CLL xenograft mouse & Leukemia & {$[36,37]$} \\
\hline$B R C A 1$ & $17 q 21.31$ & $\begin{array}{l}\text { Repair DNA double-strand breaks } \\
\text { via ubiquitination, transcriptional } \\
\text { regulation, and homologous } \\
\text { recombination. }\end{array}$ & $\begin{array}{l}\text { A2780, HEK293, } \\
\text { SUM149PT }\end{array}$ & N/A & Ovarian cancer & [38] \\
\hline$B R C A 2$ & $13 q 13.1$ & $\begin{array}{l}\text { Repair DNA double-strand breaks } \\
\text { via ubiquitination, transcriptional } \\
\text { regulation, and homologous } \\
\text { recombination. }\end{array}$ & PL2F7, Y3308Y & BRCA-deficient mouse & N/A & [39] \\
\hline CDC6 & $17 q 21.2$ & $\begin{array}{l}\text { Initiation of DNA replication; } \\
\text { regulates cell cycle. }\end{array}$ & HCT-116, HKE-3 & $\begin{array}{l}\text { KRAS-induced lung cancer } \\
\text { mouse }\end{array}$ & Lung cancer & {$[40,41]$} \\
\hline CDK1 & $10 q 21.2$ & $\begin{array}{l}\text { Regulate cell cycle (G1/S and } \\
\text { G2/M phase transitions). }\end{array}$ & LIM1215, SW48 & KRAS-mutated mouse & N/A & [42] \\
\hline CDK2 & $12 q 13.2$ & $\begin{array}{l}\text { Regulate cell cycle (G1/S phase } \\
\text { transition). }\end{array}$ & HACAT & N/A & N/A & {$[43,44]$} \\
\hline CDK17 & $12 q 23.1$ & $\begin{array}{l}\text { Serine-threonine protein kinase; } \\
\text { regulate G2/M phase transition. }\end{array}$ & $\begin{array}{l}\text { HeLa, K562, } \\
\text { MCF10A, MDA-MB- } \\
\text { 231, RPE1 }\end{array}$ & N/A & Breast cancer & [45] \\
\hline CHEK1 & $11 q 24.2$ & $\begin{array}{l}\text { Serine-threonine protein kinase; } \\
\text { triggers cell cycle arrest in response } \\
\text { to DNA damage; integrate signals } \\
\text { from ATR and ATM; phosphorylation } \\
\text { of CDC25A to delay cell cycle progression } \\
\text { following DNA double-strand breaks. }\end{array}$ & $\begin{array}{l}\text { PEO14, PEO23, } \\
\text { SKOV3 }\end{array}$ & SKOV3 xenograft mouse & Ovarian cancer & {$[46]$} \\
\hline CHEK2 & $22 q 12.1$ & $\begin{array}{l}\text { Serine-threonine protein kinase; triggers } \\
\text { cell cycle arrest in response to DNA } \\
\text { damage; integrate signals from ATR and } \\
\text { ATM; phosphorylation of CDC25A to delay } \\
\text { cell cycle progression following DNA } \\
\text { double-strand breaks. }\end{array}$ & $\begin{array}{l}\text { Cal27, HN30, } \\
\text { HN31, SCC61, } \\
\text { UMSCC17A }\end{array}$ & N/A & $\begin{array}{l}\text { Head and neck } \\
\text { cancer }\end{array}$ & [47] \\
\hline GATA2 & $3 q 21.3$ & $\begin{array}{l}\text { Zinc-finger transcription factor; regulate } \\
\text { transcription genes. }\end{array}$ & $\begin{array}{l}\text { A549, H226, } \\
\text { HL7702 }\end{array}$ & A549 xenograft mouse & Lung cancer & [48] \\
\hline KRAS & $12 \mathrm{p} 12.1$ & $\begin{array}{l}\text { Transcriptional activator that regulates } \\
\text { endothelial cells endothelin-1 gene } \\
\text { expression. }\end{array}$ & A549, H441 & A549 xenograft mouse & Lung cancer & {$[49,50]$} \\
\hline MREI1 & $11 q 21$ & $\begin{array}{l}\text { MRN complex component; DNA } \\
\text { double-strand breaks repair via } \\
\text { nonhomologous end-joining and } \\
\text { homologous recombination activation } \\
\text { in ATM-mediated checkpoint. }\end{array}$ & $\mathrm{V}-\mathrm{C} 8$ & N/A & N/A & [51] \\
\hline MYC & $8 q 24.21$ & $\begin{array}{l}\text { Regulate cell cycle progression, } \\
\text { transcription, and apoptosis. }\end{array}$ & $\begin{array}{l}\text { Kelly, BE-2C, NLF, } \\
\text { SK-N-AS, SHEP, } \\
\text { MYCN-ER }\end{array}$ & BALB/c nude mouse & Neuroblastoma & {$[52,53]$} \\
\hline$N B N$ & $8 q 21.3$ & $\begin{array}{l}\text { MRN complex component; DNA } \\
\text { double-strand breaks repair via } \\
\text { nonhomologous end-joining and }\end{array}$ & B220, Gr-1, Mac-1 & Nbn-mutated mouse & Leukemia & {$[54]$} \\
\hline
\end{tabular}


Table 2 Identified key genes in synthetic lethality preclinical studies (Continued)

\begin{tabular}{|c|c|c|c|c|c|c|}
\hline Gene & Chromosome & Cellular process and mechanism & In vitro & In vivo & Cancer type & Reference \\
\hline & & $\begin{array}{l}\text { homologous recombination } \\
\text { activation in ATM-mediated } \\
\text { checkpoint. }\end{array}$ & & & & \\
\hline PAK3 & $\mathrm{Xq23}$ & $\begin{array}{l}\text { Serine-threonine protein kinase; } \\
\text { regulates cell cycle, cell migration, } \\
\text { and apoptosis. }\end{array}$ & $\begin{array}{l}\text { CaSki, HeLa, HFK, } \\
\text { SiHa }\end{array}$ & N/A & Cervical cancer & {$[55]$} \\
\hline PARP1 & $1 q 41.42$ & $\begin{array}{l}\text { Regulate cell proliferation and } \\
\text { differentiation; repair DNA single- } \\
\text { and double-strand breaks. }\end{array}$ & $\begin{array}{l}\text { DLD-1, HEK293FT, } \\
\text { KB1P-G3, KB2P, } \\
\text { SUM149PT, U2OS }\end{array}$ & BRCA2-mutated mouse & $\begin{array}{l}\text { Breast and } \\
\text { ovarian cancer }\end{array}$ & {$[56]$} \\
\hline$P L K 1$ & $16 p 12.2$ & $\begin{array}{l}\text { Serine-threonine protein kinase; regulate } \\
\text { cell proliferation and apoptosis; triggers G2/ } \\
\text { M transition. }\end{array}$ & $\begin{array}{l}\text { A549, H441, H522, } \\
\text { T29 }\end{array}$ & $\begin{array}{l}\text { BALB/C and } \mathrm{C} 57 \mathrm{BL} / 6 \\
\text { nude mouse }\end{array}$ & Lung cancer & {$[57]$} \\
\hline RAD50 & $5 q 31.1$ & $\begin{array}{l}\text { MRN complex component; DNA double- } \\
\text { strand breaks repair via nonhomologous } \\
\text { end-joining and homologous recombin- } \\
\text { ation activation in ATM-mediated } \\
\text { checkpoint. }\end{array}$ & $\begin{array}{l}\text { D1241, L1240, } \\
\text { Q1262, WT }\end{array}$ & N/A & $\begin{array}{l}\text { Metastatic } \\
\text { small cell } \\
\text { cancer }\end{array}$ & {$[58]$} \\
\hline RAD51 & $15 q 15.1$ & $\begin{array}{l}\text { Repair DNA double-strand breaks via hom- } \\
\text { ologous recombination. }\end{array}$ & $\begin{array}{l}\text { HeLa, K562, M059, } \\
\text { U2OS }\end{array}$ & N/A & N/A & {$[59]$} \\
\hline TP53 & $17 p 13.1$ & $\begin{array}{l}\text { Major tumor suppressor; regulate cell cycle, } \\
\text { senescence, and apoptosis. }\end{array}$ & C4-2, LNCaP, U2OS & NSG mouse & $\begin{array}{l}\text { Prostate } \\
\text { cancer }\end{array}$ & {$[60,61]$} \\
\hline $53 B P 1$ & $15 q 15.3$ & $\begin{array}{l}\text { Repair DNA double-strand breaks by pro- } \\
\text { moting non-homologous end-joining path- } \\
\text { ways while limiting homologous } \\
\text { recombination. }\end{array}$ & $\begin{array}{l}\text { DOHH2, G452, } \\
\text { HCC1187 OCI-LY } \\
(1,8,19), \text { SUDHL-6, } \\
\text { U2932, VAL }\end{array}$ & NOD, NSG, and SCID mouse & Lymphoma & {$[62,63]$} \\
\hline WEE1 & $11 \mathrm{p} 15.4$ & $\begin{array}{l}\text { Serine-threonine protein kinase; regulates } \\
\text { G2/M checkpoint via CDC2 inhibition. }\end{array}$ & $\begin{array}{l}\text { MCF7, MDA-MB- } \\
\text { 231, T-47D, Zr-75-1 }\end{array}$ & $\begin{array}{l}\text { Breast cancer xenograft NSG } \\
\text { mouse }\end{array}$ & Breast cancer & [64] \\
\hline
\end{tabular}

resistance [76]. However, RNAi screens are highly prone to off-target effects that will significantly increase treatment risks, thus limiting its clinical application [77]. The consolidation of bioinformatics tools and algorithms improves library generation while reducing off-target effects and increasing the on-target robustness of RNAi sequences to enhance RNAi reagent specificity [78]. Nevertheless, the human cell culture system and RNAi library gene specificity still need to be improved to be used in human RNAi screening.

\section{CRISPR screens}

CRISPR is a compelling technology used to investigate various biological processes such as synergistic and synthetic lethal interactions. It is a scalable genome-editing technology that is highly efficient and specific which surpasses RNAi-based reagents and can be used in highthroughput screens by the utilization of multiple related approaches to discover novel drug targets $[79,80]$. The CRISPR-Cas9 system usage in human cells is based on the genome-editing technology development that pairs sequence-specific gRNAs with bacterial Cas9 expression, whereby the enzyme was guided to excise specific DNA fragments of the human genome. Such an approach can be utilized in the human cells to study the systemic effects of the loss of each gene in the genome [81]. The rapid advance in genetic tools and modifications, coupled with recent studies of the technology, provides an insight into the mechanism of CRISPR-Cas9 that will enhance target discovery approaches in the future.

\section{Bioinformatics screens}

Multiple studies have used bioinformatic screening to identify synthetic lethal pathway that can theoretically be used to monitor disease progression [82]. The predictions are produced by scoring gene pair interaction by using expression profiles data, screening results for shRNA, and copy number data [83]. Since the human genome-wide evaluation of synthetic lethal interactions is still impractical, computational data transfer of model organism interactions, ranging from yeast to humans, became the study trend $[84,85]$. New innovative programs and computational methods are now being developed to enable the rapid analysis of data sets for gene expression. Despite the limitations of expression profiling, the assimilation of computational methods with other types of data still remains as one of the leading molecular techniques for the prognosis and prediction of synthetic lethal interactions [86].

\section{Preclinic and clinical development of synthetic lethality}

Clinically, the treatment strategy based on synthetic lethality has three major benefits: (1) a synthetic lethality- 


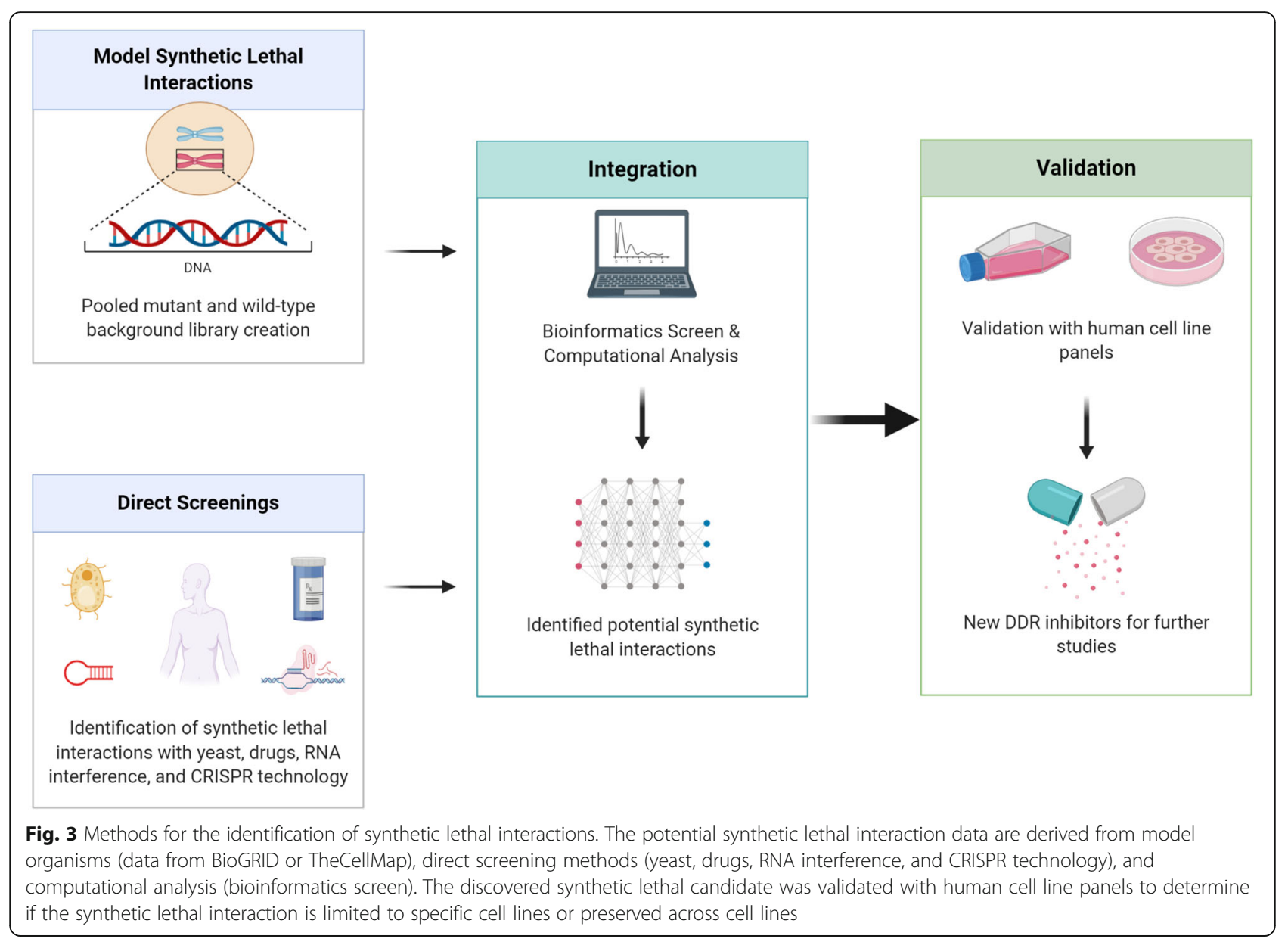

based treatment strategy could be utilized against the majority of cancer mutations, (2) synthetic lethality allows simple identification of treatment-responding patients due to its selective nature of specific cancer cell genetic mutation, and (3) combination therapy could increase the efficacy of chemotherapeutic drugs, thus allowing for lower dosage and avoiding adverse effects. Currently, the FDA has approved four PARP inhibitors for clinical anticancer therapy, including olaparib, niraparib, rucaparib, and talazoparib. The recent clinical trials for synthetic lethality treatment of tumors, including PARP inhibitors, non-PARP DDR inhibitors, and combination therapies, are summarized in Table 3.

\section{PARP inhibitors in clinical practice}

The synthetic lethal interaction among PARP and BRCA1/2 was discovered in $2005[10,11]$. PARP-1 is a DNA repair protein that regulates cell proliferation and differentiation by repairing DNA single-strand break (SSB) and double-strand break (DSB). The inhibition of PARP1 DNA damage repair by PARP inhibitors leads to deleterious mutation accumulation, resulting in genetic instability and cell death [56]. PARP inhibitors initially entered the clinical trials as combination therapy of fulldose temozolomide, a DNA alkylating agent, and lowdose rucaparib [87]. A phase 1 olaparib clinical trial, which involved patients with BRCA1/2 mutations, reported that $63 \%$ of the patients who received olaparib exhibited clinical benefit with minimal side effects than those of conventional chemotherapy regimens [16]. Subsequently, phase 2 and 3 clinical trials, which included patients with BRCA1/2-mutated breast, ovarian, pancreatic, and prostate cancers, demonstrated the clinical benefit offered by olaparib [88-92], thus providing sufficient evidence for the FDA to approve olaparib as a treatment for advanced ovarian cancer patients [93, 94].

The FDA approved niraparib as maintenance therapy for the primary peritoneal, fallopian tube, or ovarian cancer patients [95]. The phase 1 dose-escalation trial with 100 advanced solid tumor patients assessed the safety, efficacy, and tolerability of niraparib monotherapy. The results from the pharmacodynamic analysis demonstrated that anticancer activities were recorded at doses above $60 \mathrm{mg} /$ day and PARP inhibition over $50 \%$ at doses above $80 \mathrm{mg} /$ day [96]. The FDA approval of niraparib was based on the evidence from the phase 3 
Table 3 Recent clinical trials for PARP, ATR, DNA-PK, WEE1, and CHK1 inhibitors: monotherapy and combination therapy

\begin{tabular}{|c|c|c|c|c|c|}
\hline Target & Agent & Intervention & Cancer Type & Phase & $\begin{array}{l}\text { ClinicalTrials.gov } \\
\text { identifier }\end{array}$ \\
\hline \multirow[t]{23}{*}{ PARP } & \multirow[t]{5}{*}{ Olaparib } & Olaparib & Breast and ovarian cancer & IV & NCT04330040 \\
\hline & & Olaparib + Paclitaxel + Durvalumab & Advanced gastric cancer & $\|$ & NCT03579784 \\
\hline & & Olaparib + Abiraterone & Prostate cancer & III & NCT03732820 \\
\hline & & Olaparib + Durvalumab & Bladder cancer & $\|$ & NCT03534492 \\
\hline & & Olaparib + Temozolomide & Colorectal cancer & $\|$ & NCT04166435 \\
\hline & \multirow[t]{5}{*}{ Niraparib } & Niraparib & Pancreatic cancer & $\|$ & NCT03601923 \\
\hline & & Niraparib + Osimertinib & Lung cancer & । & NCT03891615 \\
\hline & & Niraparib + Dostarlimab & Ovarian cancer & III & NCT03602859 \\
\hline & & Niraparib + MGD013 & $\begin{array}{l}\text { Gastric and gastroesophageal junction } \\
\text { cancer }\end{array}$ & । & NCT04178460 \\
\hline & & Niraparib + Dostarlimab & Cervix cancer & $\|$ & NCT04068753 \\
\hline & \multirow[t]{5}{*}{ Rucaparib } & Rucaparib & Endometrial cancer & $\|$ & NCT03617679 \\
\hline & & Rucaparib + Nivolumab & Biliary tract cancer & $\|$ & NCT03639935 \\
\hline & & Rucaparib + Radiotherapy & Breast cancer & I & NCT03542175 \\
\hline & & Rucaparib + Copanlisib & Prostate cancer & I & NCT04253262 \\
\hline & & Rucacparib + Enzalutamide + Abiraterone & Prostate cancer & I & NCT04179396 \\
\hline & \multirow[t]{8}{*}{ Talazoparib } & Talazoparib & Leukemia & । & NCT03974217 \\
\hline & & Talazoparib + Avelumab & Breast cancer & । & NCT03964532 \\
\hline & & Talazoparib + Radiotherapy & Gynecologic cancer & I & NCT03968406 \\
\hline & & Talazoparib + ASTX727 & Breast cancer & । & NCT04134884 \\
\hline & & Talazoparib + Avelumab & Lung cancer & $\|$ & NCT04173507 \\
\hline & & Talazoparib + Axitinib & Kidney cancer & $|/| \mid$ & NCT04337970 \\
\hline & & Talazoparib + Atezolizumab & Lung cancer & $\|$ & NCT04334941 \\
\hline & & Talazoparib + Gedatolisib & Breast cancer & $\|$ & NCT03911973 \\
\hline \multirow[t]{15}{*}{ ATR } & \multirow{5}{*}{$\begin{array}{l}\text { Berzosertib } \\
\text { (M6620) }\end{array}$} & Berzosertib + Radiotherapy & Lung cancer & । & NCT02589522 \\
\hline & & Berzosertib + Radiotherapy & Breast cancer & I & NCT04052555 \\
\hline & & Berzosertib + Topotecan & Lung cancer & $|/| \mid$ & NCT02487095 \\
\hline & & Berzosertib + Topotecan Hydrochloride & Lung cancer & $\|$ & NCT03896503 \\
\hline & & Berzosertib + Carboplatin + Docetaxel & Prostate cancer & $\|$ & NCT03517969 \\
\hline & \multirow[t]{5}{*}{ AZD6738 } & AZD6738 + Radiotherapy & Advanced solid tumors & I & NCT02223923 \\
\hline & & AZD6738 + Olaparib & Gynecologic cancer & $\|$ & NCT04065269 \\
\hline & & AZD6738 + Olaparib + Durvalumab & Breast cancer & $\|$ & NCT03740893 \\
\hline & & AZD6738 + Acalabrutinib & Chronic lymphocytic leukemia & $|/| \mid$ & NCT03328273 \\
\hline & & AZD6738 + Durvalumab & Biliary tract cancer & $\|$ & NCT04298008 \\
\hline & \multirow[t]{3}{*}{ BAY1895344 } & BAY1895344 & Advanced solid tumors & I & NCT03188965 \\
\hline & & BAY1895344 + Pembrolizumab & Advanced solid tumors & । & NCT04095273 \\
\hline & & BAY1895344 + Niraparib & Ovarian cancer & । & NCT04267939 \\
\hline & \multirow[t]{2}{*}{ M4344 } & M4344 + Niraparib & Ovarian cancer & । & NCT04149145 \\
\hline & & M4344 + Carboplatin & Advanced solid tumors & । & NCT02278250 \\
\hline \multirow{4}{*}{$\begin{array}{l}\text { DNA- } \\
\text { PK }\end{array}$} & \multirow[t]{2}{*}{ CC-115 } & CC-115 & Advanced solid tumors & । & NCT01353625 \\
\hline & & CC-115 + Enzalutamide & Prostate cancer & । & NCT02833883 \\
\hline & AZD7648 & $\begin{array}{l}\text { AZD7648 + Olaparib + Pegylated Liposomal } \\
\text { Doxorubicin }\end{array}$ & Advanced solid tumors & $|/| \mid$ & NCT03907969 \\
\hline & M9831 (VX-984) & M9831 - - - - r - & Advanced solid tumors & 1 & NCT02644278 \\
\hline
\end{tabular}


Table 3 Recent clinical trials for PARP, ATR, DNA-PK, WEE1, and CHK1 inhibitors: monotherapy and combination therapy (Continued)

\begin{tabular}{|c|c|c|c|c|c|}
\hline Target & Agent & Intervention & Cancer Type & Phase & $\begin{array}{l}\text { ClinicalTrials.gov } \\
\text { identifier }\end{array}$ \\
\hline & $\begin{array}{l}\text { Nedisertib } \\
\text { (M3814) }\end{array}$ & $\begin{array}{l}\text { Nedisertib + Pegylated Liposomal Doxorubicin } \\
\text { Hydrochloride }\end{array}$ & Ovarian cancer & I & NCT04092270 \\
\hline & & Nedisertib + Avelumab + Radiotherapy & Hepatobiliary cancer & $|/| \mid$ & NCT04068194 \\
\hline & & Nedisertib + Avelumab + Radiotherapy & Advanced solid tumors & I & NCT03724890 \\
\hline \multirow[t]{8}{*}{ WEE1 } & \multirow{8}{*}{$\begin{array}{l}\text { Adavosertib } \\
\text { (AZD1775) }\end{array}$} & Adavosertib & Advanced solid tumors & I & NCT01748825 \\
\hline & & Adavosertib & Advanced solid tumors & $\|$ & $\begin{array}{l}\text { NCT03253679 / } \\
\text { NCT03284385 }\end{array}$ \\
\hline & & $\begin{array}{l}\text { Adavosertib + Gemcitabine + Cisplatin + } \\
\text { Carboplatin }\end{array}$ & Advanced solid tumors & I & NCT00648648 \\
\hline & & Adavosertib + Olaparib & $\begin{array}{l}\text { Ovarian, primary peritoneal, and fallopian } \\
\text { tube cancer }\end{array}$ & $\|$ & NCT03579316 \\
\hline & & Adavosertib + Olaparib + AZD6738 & Breast cancer & $\|$ & NCT03330847 \\
\hline & & Adavosertib + Irinotecan & Advanced solid tumors & $|/| \mid$ & NCT02095132 \\
\hline & & Adavosertib + Cisplatin + Radiotherapy & Cervical, vaginal, and uterine cancer & । & NCT03345784 \\
\hline & & Adavosertib + Temozolomide + Radiotherapy & Glioblastoma & I & NCT01849146 \\
\hline \multirow[t]{6}{*}{ CHK1 } & \multirow[t]{2}{*}{ SRA737 } & SRA737 & Advanced solid tumors & $|/| \mid$ & NCT02797964 \\
\hline & & SRA737 + Gemcitabine + Cisplatin & Advanced solid tumors & $|/| \mid$ & NCT02797977 \\
\hline & \multirow{4}{*}{$\begin{array}{l}\text { Prexasertib } \\
(\text { LY2606368) }\end{array}$} & Prexasertib & Advanced solid tumors & । & NCT01115790 \\
\hline & & Prexasertib & Lung cancer & $\|$ & NCT02735980 \\
\hline & & Prexasertib & Breast, ovarian, and prostate cancer & $\|$ & NCT02203513 \\
\hline & & $\begin{array}{l}\text { Prexasertib + Cisplatin + Cetuximab + } \\
\text { Radiotherapy }\end{array}$ & Head and neck cancer & I & NCT02555644 \\
\hline
\end{tabular}

NOVA trial with 553 platinum-sensitive recurrent ovarian cancer patients. Based on the phase 1 trial results [96], patients in the NOVA trial received niraparib 300 $\mathrm{mg} /$ day for 28-day cycles. Patients that received niraparib had a significantly longer progression-free survival (PFS) despite the germline BRCA mutation status (21.0 vs. 5.5 months for BRCA-mutated group; 9.3 vs. 3.9 months for non-BRCA-mutated group; hazard ratio $0.45, P<0.001$ for all groups) [97]. The most common niraparib adverse effects are thrombocytopenia, neutropenia, nausea, fatigue, and anemia, which could be controlled with dosage modifications [96, 97].

In addition, rucaparib has demonstrated an increase in maintenance setting PFS [98]. In phase 2 ARIEL trial assessing rucaparib, 206 high-grade ovarian carcinoma patients were categorized into three different groups based on the features of the tumor genome. The BRCA-mutant group has the best PFS, followed by the high chromosomal loss of heterozygosity group with a slightly more benefit over the low chromosomal loss of heterozygosity group (median PFS 12.8 vs. 5.7 vs. 5.2 months, respectively) [99]. Subsequently, the phase 3 ARIEL trial with 564 platinum-sensitive ovarian cancer patients confirmed that rucaparib significantly improved PFS (16.6 vs. 5.4 months for rucaparib and placebo group, respectively) [100]. Furthermore, ARIEL 3 demonstrated that PARP inhibitors could be used in platinum-sensitive ovarian cancer patients with previous platinum-based chemotherapy treatment. Therefore, according to the clinical trial results, rucaparib was approved by the FDA to treat BRCA1/2mutated advanced ovarian cancer patients that received two or more chemotherapies [99, 100].

Talazoparib recently received FDA approval to treat HER2-negative, BRCA-mutated advanced breast cancer patients [101]. The phase 1 trial, consisting of 18 BRCA1/2-mutated advanced breast cancer patients receiving talazoparib monotherapy (1 mg QD), demonstrated $86 \%$ clinical benefit rate with $50 \%$ response rate at 24 weeks (median PFS 34.6 weeks) [102]. The most frequent side effects of talazoparib include thrombocytopenia, fatigue, and anemia. Phase 2 ABRAZO trial with 84 BRCA1/2-mutated metastatic breast cancer patients receiving talazoparib monotherapy resulted in a $37 \%$ response rate for patients who previously received more than two advanced breast cancer cytotoxic regimens without exposure to platinum chemotherapy and $21 \%$ response rate for patients who previously are responsive to platinum chemotherapy (median PFS 5.6 vs. 4.0 months, respectively) [103]. Subsequently, the phase 3 EMBRACA trial with 431 BRCA1/2-mutated advanced breast cancer patients, talazoparib monotherapy exhibits significant PFS benefit 
when compared with standard chemotherapy, with the talazoparib group objective responsive rate significantly higher than the standard chemotherapy group $(62.6 \%$ vs. 27.2\%, respectively; $P<0.001$ ) [104]. These results indicate that talazoparib has significant PFS and overall survival improvements, leading to the recent approval of talazoparib by the FDA.

Although early clinical trials regarding synthetic lethality were focused on PARP inhibitors efficacy in germline-mutated BRCA1/2 cancers, further studies discovered that the responses are not limited to tumors with these mutations [16]. The clinical assessment of PARP inhibitors approved by the FDA is summarized in Fig. 4. In order to increase patients that would benefit from treatments based on synthetic lethality, tremendous efforts are being made to identify mutations that are susceptible to PARP and other DDR inhibitors in the HR pathway.

\section{Synthetic lethality beyond PARP inhibitors}

The revelation of synthetic lethality in various DNA repair pathways expanded DDR and DNA repair-targeting clinical strategies, with various DDR inhibitors in preclinical and clinical development. The encouraging results from PARP inhibitors led to an increasing amount of research focused on targeting other DDR pathway components as synthetic lethal approaches for cancer treatment. The lessons learned from PARP inhibitors and a comprehensive understanding of the DDR pathways are being combined to maximize the potential and clinical success of DDR inhibitors. The inhibition of DDR pathways such as ataxia telangiectasia and Rad3related (ATR) inhibitors, DNA-dependent protein kinase (DNA-PK) inhibitors, WEE1 inhibitors, and checkpoint kinase $1 / 2(\mathrm{CHK} 1 / 2)$ inhibitors have shown promising results clinically.

\section{ATR mechanisms and inhibitors}

ATR and ATM are one of the primary targets of DDR inhibitors due to its central regulatory function that works through overlapping but distinct pathways to activate DDR [105]. In the initial phase of homologous recombination (HR), DNA end resection leads to stalled replication forks that activates ATR by replication

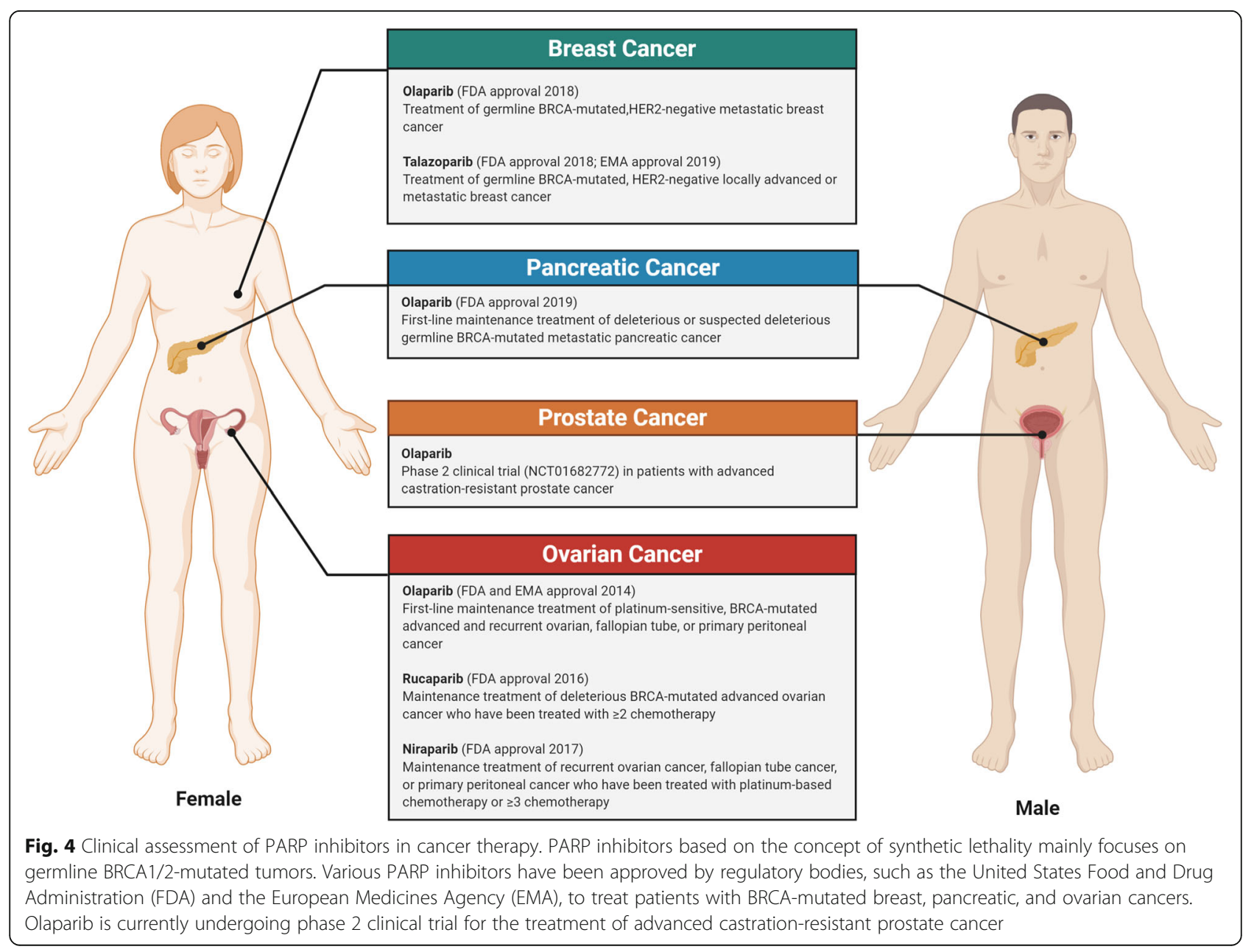


protein A (RPA)-bound ssDNA [106]. RPA-ssDNA is induced through the TOPBP1 complex with Claspin, RHINO, RAD9-RAD1-HUS1 complex, and RAD17RFC2-5 clamp loader, which activates ATR to RPAssDNA via ATR-interacting protein [59]. In contrast, ATM responds to the generated DNA DSB throughout the cell cycle and promotes DSB repair. Following the detection of DNA DSBs, it has been reported that ATM is primarily activated by interacting with NBS1 from the MRN complex [107]. Oncogene activation and loss of G1 checkpoint control that drives cancer cell replication, leading to the cancer cell dependency on the S and G2/ $M$ checkpoints and increased replication stress when cancer cells enter the $S$ phase [108]. In addition, chemotherapy, radiotherapy, and cancer-associated inflammation also result in higher replication stress. Therefore, the synthetic lethal interaction can be exploited as the result of increased dependency on the $\mathrm{S}$ and G2/M checkpoints mediated by ATR due to the heightened replication stress as the cancer cells enter $\mathrm{S}$ phase. Since ATR is crucial in the intra-S and G2/M phase cell cycle checkpoints, ATR inhibitors cause DNA damage accumulation and cell death by selectively targeting tumor cells with DNA damage-induced G1 cell cycle checkpoints defects [109].

Despite the limited data on ATR inhibitor efficacy in the clinics, patients with ATM-mutated cancer that receives an ATR inhibitor shows a complete clinical response [110]. The four ATR inhibitors that are undergoing clinical trials include berzosertib, AZD6738, BAY1895344, and M4344. Berzosertib has been tested in several clinical trials as a monotherapy and combination therapy $[111,112]$. Patients receiving berzosertib monotherapy demonstrated fine tolerance and no doselimiting toxicities. The pharmacodynamic studies of phase 1 clinical trial of berzosertib plus topotecan in 21 patients with advanced solid tumors revealed that ATR inhibition leads to enhanced DNA DSBs, resulting in stabilized or improved symptoms for patients (median PFS 10.2 months; confidence interval 95\%, 1.4 to 10.2 months) [112]. In addition, the on-going phase 1 PATR IOT trial with advanced solid tumor patients is assessing the safety and efficacy of AZD6738 monotherapy. Due to the observed bone marrow suppression after continuous dosing beyond the first cycle, various dosing schedules are being examined to improve the long-term tolerability of the patients [113]. Currently, BAY1895344 and M4344 are being tested in phase 1 clinical trial in combination with chemotherapies and as monotherapy for advanced solid tumor patients.

\section{DNA-PK mechanisms and inhibitors}

It has been reported that DNA-PK suppresses tumor growth by regulating the transcription of cancer-related pathways genes in vitro, in vivo, and ex vivo [114]. It is an essential enzyme in the PI3K-mTOR family that functions in the non-homologous end joining (NHEJ) DNA repair pathway, a predominant DSB DNA repair pathway [110]. DNA-PK comprises of DNA-PKcs, a catalytic subunit, and $\mathrm{Ku}$, which is activated by the binding of $\mathrm{Ku}$ to DNA DSBs, leading to major NHEJ protein recruitment such as DNA-PKcs, LIG4, PAXX, XLF, and XRCC4. NHEJ core complex is destabilized upon the autophosphorylation of DNA-PKcs, resulting in Ku inward sliding on the DNA and facilitating the access of ligation enzymes to repair DNA ends [115]. It has been demonstrated that BRCA1 deficiency with genetic or pharmacological inactivation of DNA-PK results in synthetic lethality. BRCA1 deficiency is commonly associated with the decreased expression of key factors in alternative NHEJ and base excision repair (BER), specifically apurinic/apyrimidinic endonuclease 1 (APE1), DNA polymerase $\mathrm{b}(\mathrm{POLB})$, and $\mathrm{X}$-ray repair cross-complementing 1 (XRCC1) [116]. Impaired BER and alternative NHEJ repair pathway inhibition results in the decreased expression of these factors, leading to the accumulation of unrepaired SSBs and ensuing DSBs [117]. In addition, cancer cells with overexpressed MYC oncogene are reported to be synthetically lethal to DNA-PK inhibition, supposedly due to increased MYC-driven DNA damage and the cancer cell reliance on the DDR pathways [118].

There are four DNA-PK inhibitors that are undergoing clinical trials, including CC-115, AZD7648, M9831, and nedisertib. CC-115, a small-molecule mTOR and DNAPK inhibitor [119], is undergoing phase 1 clinical trial which includes 44 advanced solid or hematologic malignancy patients receiving CC-115 monotherapy. The most common adverse event for CC-115 is hyperglycemia, which is associated with the inhibition of mTOR complex 1 and 2 [120]. In addition, AZD7648 is a toxic and highly selective DNA-PK inhibitor that has been shown to induce genomic instability, inhibit cell growth, and apoptosis in ATM-deficient cells, when used in combination with olaparib [121]. Based on the AZD7648 preclinical data, phase $1 / 2 \mathrm{a}$ clinical trial consisting of 234 patients receiving AZD7648 alone and in combination with olaparib has recently been initiated [122]. Furthermore, M9831 and nedisertib are currently in phase 1 clinical trials under monotherapy and in combination with chemotherapies for advanced solid tumor patients.

\section{WEE1 mechanisms and inhibitors}

WEE1 protein kinase has been reported to inhibit CDK 1 and 2, which activates G2/M cell cycle checkpoint, resulting in temporary cell cycle arrest and DNA damage repair. Hence, WEE1 inhibitors prevent the activation of G2/M cell cycle checkpoint, resulting in the loss of 
genomic integrity due to increased replication stress [123]. The inhibition of WEE1 protein kinase produces replication-dependent intracellular DNA damage due to abnormal DNA replication through CDK 2 inhibition [64]. In addition, p53 regulates the G1 cell cycle checkpoint, which leads to an increased reliance on the G2 cell cycle checkpoint of p53-deficient cells. Thus, WEE1 inhibitors are used to target p53-deficient tumors. Several preclinical studies confirmed that WEE1 inhibitors cause mitotic lethality, making p53-deficient cells sensitive to radiation and DNA damaging agents [124, 125]. For instance, Liang et al. [126] reported that apoptosis induced by accumulated DNA damage increases the sensitivity of cancer cells to WEE1 inhibitors. WEE1 inhibitor can selectively inhibit the proliferation of glioma and hepatocellular carcinoma cells with ATRX mutations, which indicates that the synthetic lethal interaction between ATRX and WEE1 can be applied in an extensive range of tumors. Therefore, researchers are focusing on the synergistic activity of WEE1 inhibitors with different DNA damaging agents.

Adavosertib is the only WEE1 inhibitor that is currently undergoing clinical trials. The preclinical data demonstrate that adavosertib inhibits the G2 cell cycle checkpoint and renders p53-deficient tumor cells vulnerable to radiation and DNA-damaging chemotherapies $[127,128]$. The phase 1 clinical trial with 25 refractory solid tumor patients reported that two BRCA-mutated tumor patients in the study have partial response to adavosertib monotherapy [129]. Moreover, another phase 1 clinical trial consisting of 202 advanced solid tumor patients receiving adavosertib in combination with chemotherapies resulted in 53\% disease stabilization and 10\% partial response [130]. Both of which confirmed the safety and efficacy of adavosertib monotherapy and in combination with chemotherapy. Subsequently, the phase 2 trial with 24 p53-mutated ovarian cancer patients receiving adavosertib plus carboplatin reported that the overall response rate was $43 \%$ (confidence interval $95 \%, 22 \%$ to $66 \%$ ) [131]. The main adverse effects reported by the adavosertib clinical trials were fatigue, nausea, and thrombocytopenia.

\section{CHK1 mechanisms and inhibitors}

CHK1 and 2 are cell cycle checkpoint kinases in the DDR pathway that are targeted by ATR and ATM, respectively. It prevents cell cycle progression when DNA damage is detected and being repaired [132]. CHK1 kinase has several targets that facilitate the $\mathrm{S}$ and $\mathrm{G} 2 / \mathrm{M}$ phase cell cycle checkpoint arrest and could phosphorylate and degrade CDC25A, CDC25B, and CDC25C phosphatases at multiple sites, resulting in increased CDK protein phosphorylation and inhibition [133]. Rogers et al. [134] indicated that the silencing of DNA polymerase family $\mathrm{B}$ subunits (POLE, POLE2, and POLA) results in an increased sensitivity of colorectal cancer (SW620) and non-small cell lung cancer (A549) cells to CHK1 inhibitors. The depletion of DNA polymerase family B coupled with CHK1 inhibitor leads to increased DNA damage, replication stress, and apoptosis in cancer cells. Furthermore, treatment-induced inhibition of DNA polymerase family B via CD437 or aphidicolin with CHK1 inhibitor synergistically inhibited the proliferation of cancer cells. Moreover, CHK1 has been reported to activate WEE1 kinase and inhibit CDK1 [135]. Hence, CHK1 inhibitors were developed to facilitate DNA-damaged cell progression.

Multiple studies have reported that CHK1 inhibitors are highly synergistic with replication-dependent DNA damage generating drugs, thus combination therapy with such drugs is focused during clinical development [136, 137]. CHK1 inhibitors have been developed and tested with various drugs incessantly due to toxicity concerns. The current ongoing clinical trials for CHK1-selective inhibitors include SRA737 and prexasertib. SRA737 is an oral CHK1 inhibitor that is in phase 1 and 2 clinical trials as a monotherapy and in combination with low-dose gemcitabine for non-Hodgkin's lymphoma and advanced solid tumor patients [137]. In addition, the secondgeneration $\mathrm{CHK} 1$ inhibitor prexasertib is also being tested in the clinical trials. The phase 1 trial reported that transient neutropenia was frequently observed in patients receiving prexasertib monotherapy [138, 139]. Subsequently, the phase 2 prexasertib trial consisting of 28 high-grade serous ovarian cancer patients demonstrated a 29\% partial response (confidence interval 95\%, $13 \%$ to $49 \%$ ) for prexasertib monotherapy, with the most common adverse effects being decreased white blood cell count and neutropenia [140].

\section{Combination therapies DDR inhibitors and DNA-damaging agents}

As previously mentioned, PARP inhibitors cause irreparable cytotoxicity by inducing the collapsing/stalling of the DNA replication fork to block cellular replication and inhibiting repair protein recruitment at DNAdamaged sites. PARP inhibitors were initially designed to make tumors vulnerable to DNA-damaging agents such as radiation and chemotherapeutic agents. Indeed, PARP inhibitors succeeded in sensitizing tumor cells to topoisomerase 1 inhibitors (e.g., camptothecin) and radiation [141]. However, it has been reported that the combination of PARP inhibitors with doxorubicin, gemcitabine, and taxan has no significant synergistic effects [142]. Lu et al. [143] indicated that PARP inhibitors determine the efficacy of the combination therapy with the same chemotherapeutic agent. For instance, a randomized phase 2 trial reported that veliparib, a potent PARP inhibitor, 
has higher PFS and overall survival in patients treated with veliparib combined with carboplatin/paclitaxel compared to patients treated with veliparib combined with temozolomide (median PFS 14.1 vs. 7.4 months and median overall survival 28.3 vs. 19.1 months, respectively) [144]. Each therapeutic agent can act according to the defined molecular mechanism while having a limited effect on other agents in combination therapy. Hence, combination therapies with PARP inhibitors could be utilized based on the dual molecular mechanism in various types of solid tumors. Moreover, DDR inhibitors have been combined with DNA-damaging agents in multiple clinical trials. In order to maximize synergistic anticancer efficacy, a complete understanding of the DNA damage induced by the respective pathways inhibition and various chemotherapies are required. Nonetheless, it is imperative to consider the toxicities resulted from such combinations. The limitations for combination therapies could be overcome by a precise selection of cancer patients with specific phenotypes or genotypes and a thorough analysis of the combination drug administration sequence, to optimize the synergistic effect of the drugs.

\section{DDR inhibitors and immune checkpoint inhibitors}

Recently, various studies have reported that PARP inhibitors could enhance the efficacy of immune checkpoint inhibitors by alleviating resistance through immune microenvironment modification and inducing crosspresentation [145]. The combination of PARP inhibitors with immune checkpoint inhibitors demonstrated promising results in ovarian cancer treatment. The DNA damage induced by PARP inhibitors enhances immune priming through various molecular mechanisms and upregulates the expression of programmed death-ligand 1 (PD-L1) [146]. Ding et al. [147] showed that olaparib activated the stimulator of interferon genes (STING) pathway and increased the expression of C-X-C motif chemokine ligand 10 (CXCL10), interferon-beta (IFN- $\beta$ ), and PD-L1 in high-grade serous ovarian cancer mice model with p53 and BRCA1 deficiency and c-MYC overexpression. The combination of programmed cell death protein 1 (PD-1) inhibitor with olaparib enhanced the treatment efficacy of olaparib, whereas anti-PD-1 monotherapy shows no effect. Likewise, Shen et al. [148] demonstrated that talazoparib also activated the STING pathway and increased the expression of chemokine ligand 5 (CCL5), CXCL10, and PD-L1. Talazoparib and anti-PD-L1 antibody combination therapy exhibited synergistic activity in the HR proficient ID8 mice model. Furthermore, the phase 1 clinical trial consisting of 9 female patients with women's cancer (ovarian, endometrial, and breast cancer) receiving a combination of durvalumab (PD-L1 inhibitor), cediranib (VEGFR1-3), and olaparib reported $67 \%$ clinical benefit rate (44\% partial response and $33 \%$ stable disease $\geq 6$ months) without dose-limiting toxicities [149]. The phase 2 expansion study is currently being conducted with recurrent ovarian cancer patients.

Various studies have shown that other DDR inhibitors, such as ATR, WEE1, and CHK1 inhibitors, have synergistic effects with immune checkpoint inhibitors. Sheng et al. [150] demonstrated that AZD6738 enhances the efficacy of immune checkpoint inhibitors and radiotherapy in hepatocellular carcinoma. The synergistic antitumor effect of AZD6738 and radioimmunotherapy combination therapy depended on cyclic GMP-AMP synthase (cGAS)/STING signaling pathway activation. AZD6738 increased cell proliferation, infiltration, and interferongamma (IFN- $\gamma$ ) production of tumor-infiltrating lymphocyte $\mathrm{CD}^{+} \mathrm{T}$ cells, resulting in decreased $\mathrm{T}$ cells and tumor-infiltrating lymphocyte Tregs in mice xenografts. Moreover, Patel et al. [151] indicated that adavosertib and ionizing radiation combination therapy enhanced the sensitivity to T-lymphocyte, tumor-specific cytotoxicity, and programmed death-axis immune checkpoint blockade response in various cancers such as melanoma, lung carcinoma, and head and neck carcinoma in vitro and in vivo. The addition of adavosertib after ionizing radiation reversed the G2/M cell cycle checkpoint activation and led to cell death. Adavosertib and ionizing radiation combination therapy promote the accumulation of M-phase DNA damage in cells, resulting in mitotic catastrophe. In addition, Sen et al. [137] reported that SRA737 and anti-PD-L1 combination therapy significantly decreased the population of myeloidderived suppressor cells and immunosuppressive M2 macrophages and increased the expression of CCL5, CXCL10, and IFN- $\beta$, which enhances the anti-cancer immune response in multiple cancer cells.

\section{Synthetic lethality limitations and drug resistance}

There are several limitations in the development of synthetic lethal drugs (Fig. 5). First, cancers generally do not rely on one DNA repair pathway to survive. The DNA repair pathways could overlap and result in the resistance of a synthetically lethal drug [110]. Second, most DNA repair pathways have similar DNA repair proteins instead of independent domains. Thus, the synthetic lethal drugs that inhibit a single DNA repair component may have off-target side effects, in which the shared domain of the targeted repair component of another important protein is also inhibited. Furthermore, these DDR inhibitors may increase the side effects of anticancer drugs and DNA damage on normal tissue, which increases the risk of secondary malignancies. Third, the tumor-specific DNA repair components for various cancer types are not well defined [152]. 


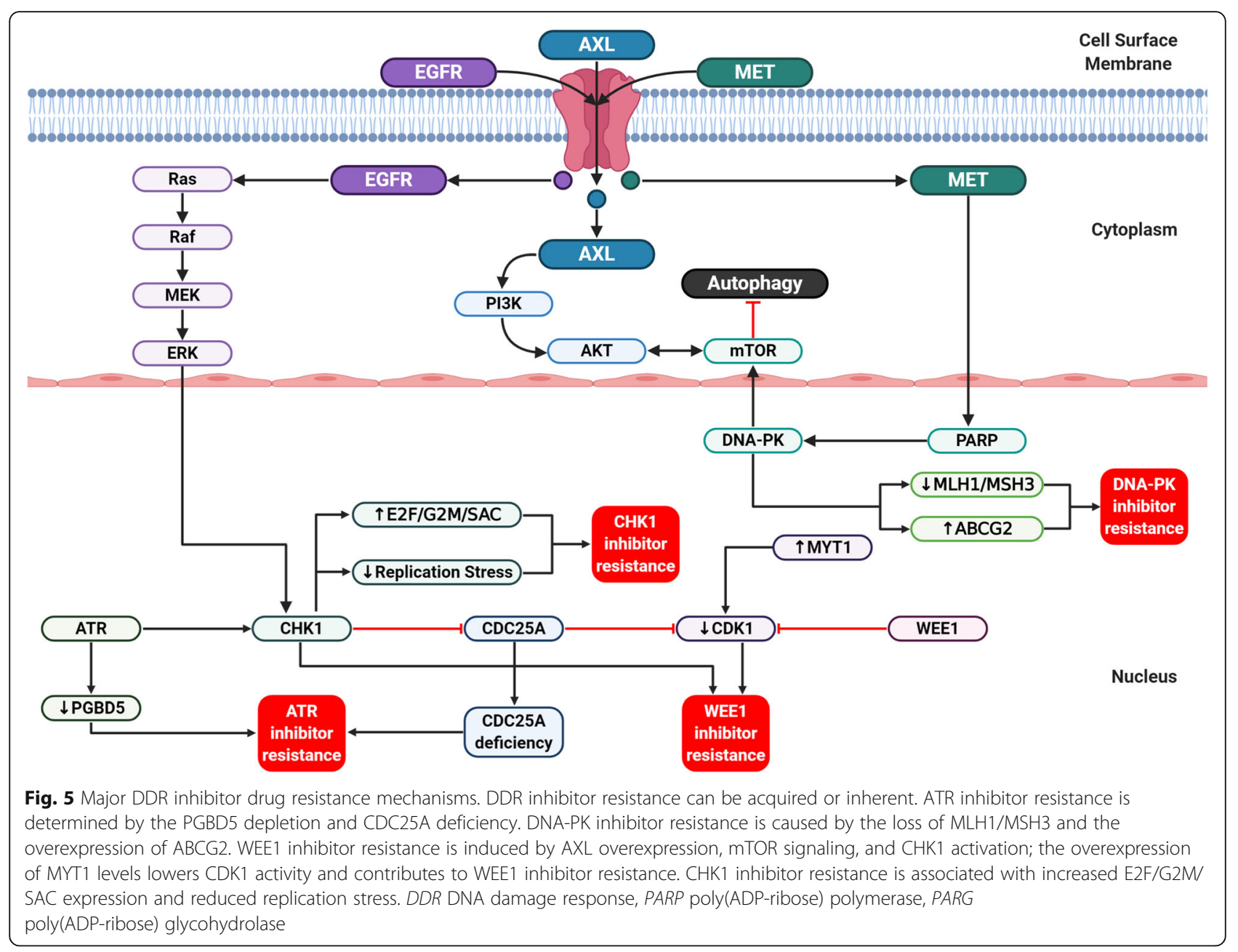

However, this issue could be overcome as genome-wide sequencing for various tumors are further reported.

\section{Resistance to PARP inhibitors}

Since PARP inhibitors have been used clinically over an extended period of time, it has been reported that cancers resistance to PARP inhibitor is multifactorial and can either be acquired or inherent [153]. Replication stress mitigation, a process which tumor cell stabilizes the replication forks and slow down the cell cycle by various pathways, is crucial in the cancer resistance to PARP inhibitors [154]. The increased protection of the replication fork and the decreased proliferation through mechanisms, such as the dependence on the ATR-CHK1 replication checkpoint pathway and the loss of EZH2 or MLL3/4 for DNA repair, lead to the resistance of PARP inhibitors [155]. Preclinical studies have reported that the mechanisms of PARP inhibitors resistance are associated with HR repair activity restoration. HR repair functions could be restored through indirect mechanisms, such as signals that increase the expression or activity of the HR machinery, and direct mechanisms, including epigenetic, genomic, or post-translational variations in the HR machinery. Secondary mutations across various cancer types were discovered to cause the reversion of DDR protein or gene function, such as BRCA1/2, PALB2, and RAD51C/D, resulting in the restoration of HR repair function and nullifying synthetic lethality $[156,157]$. In addition, the loss of 53BP1, resulting in DNA repair balance shifting from NHEJ to HR, is associated with PARP inhibitors resistance [62]. Most PARP inhibitor resistance biomarkers do not rely on one DDR pathway. For instance, cancer cell resistance to PARP inhibitors can emerge through the loss or mutations of PARP1 and lead to a decrease of PARP inhibitor binding. The insufficient PAR glycohydrolase (PARG) activity raises the auto-PARylation of PARP1, resulting in the restoration of PARP signaling which releases PARP1 from the DNA and decreases the DNA damage efficacy of PARP inhibitors [56, 158].

\section{Resistance to ATR inhibitors}

Thus far, ATR inhibitor resistance has not been reported in clinical studies. However, several preclinical studies 
have identified the mechanism of ATR inhibitor resistance in vitro. Henssen et al. [159] recently reported that endogenous PGBD5 depletion is associated with AZD6738 resistance in human tumor cells. AZD6738 causes unrepaired DNA damage to be accumulated in PGBD5-expressing cells, resulting in G1-phase and dividing cell apoptosis. Ruiz et al. [160] indicated that CDC25A determines ATR inhibitor sensitivity. CDC25A-deficient cells do not enter mitosis prematurely, which leads to the resistance of high dose ATR inhibitors. However, WEE1 inhibitors force CDC25Adeficient cells to enter mitosis and could restore the cytotoxicity of ATR inhibitors.

\section{Resistance to DNA-PK inhibitors}

The molecular mechanisms of DNA-PK inhibitor resistance have been explored by several studies. It has been reported that KU60648, a DNA-PK inhibitor, is sensitive to the loss of MMR protein MSH3 in MLH1-deficient cells [161]. Hinrichsen et al. [162] discovered that MLH1-deficient cells are sensitive to KU60648 compared with overexpressed MLH1 or MMR-proficient cells due to the decreased DSB repair capacity. Moreover, Beebe et al. [163] indicated that the overexpression of ATP-binding cassette G2 (ABCG2), an ATP-binding cassette transporter superfamily member, increases CC115 resistance. Since CC- 115 is a substrate of ABCG2, its potency is affected by ABCG2 expression; thereby the inhibition of ABCG2 via small molecular inhibitors, tumor cells will be sensitive to CC-115.

\section{Resistance to WEE1 inhibitors}

Although adavosertib has shown promising results in the clinical trials, drug resistance is inevitable. Sen et al. [164] demonstrated that AXL and phosphorylated ribosomal S6 (pS6) induces WEE1 inhibitor resistance through downstream mTOR signaling and the activation of CHK1. Adavosertib-resistant cells exhibit high AXL and pS6 expression level, thus WEE1 inhibitors combined with AXL or mTOR inhibitors could overcome adavosertib resistance. In addition, AXL activates the ERK pathway to recruit and activate CHK1. Adavosertib-resistant cells have overexpressed AXL, MET, and pS6 levels that could be overcome with AXL or mTOR inhibitors. Likewise, Li et al. [165] reported that the complementary activated mTOR pathway facilitates resistance to WEE1 inhibitors. Thus, the dual inhibition of WEE1 and mTOR will induce extensive DNA replication stress, resulting in replication fork stalling, DNA damage, and cell death. Furthermore, Lewis et al. [166] found that cells with acquired resistance to adavosertib following its treatment have high MYT1 expression levels compared to sensitive cells. The suppression of MYT1 promoted CDK1 activity and helped overcome adavosertib resistance.

\section{Resistance to CHK1 inhibitors}

Recently, it has been reported that the acquired resistance of prexasertib is associated with innate immunity [167, 168]. Blosser et al. [168] identified the correlation between prexasertib resistance with innate immunity genes and described the association between the sensitivity of prexasertib and the expression of E2F target genes. The expression of immune-related and E2F/ G2M/SAC genes contributes to prexasertib resistance. The increased E2F/G2M/SAC expression and reduced replication stress or DNA damage are highly associated with NCI-H520 lung cancer cell resistance to prexasertib. Similarly, Manic et al. [169] confirm that an experimental increase of replication stress in advanced colorectal cancer cells eliminates the resistance to prexasertib. The decrease in oncogene-induced replication stress will reduce the stress generated by $\mathrm{CHK} 1$ inhibitors and lead to acquired drug resistance.

\section{The future of synthetic lethality}

The recent discovery of PARP inhibitors leads to researches regarding genetic associations between potential therapeutic targets and cancer genes for BRCA1/2mutated cancer patients [5]. However, the limits of sequence-based cancer genetic target discovery have almost been reached. Nonetheless, various targets for cancer drugs could still be discovered with technological advances. CRISPR-based genomic screenings can be used in various ways to deliver the next generation of targeted therapies, and address the loss of nonautonomous cell pathways, tumor suppressor genes, and unmarked oncogenes [170]. Since solid tumors are generally powered by a variety of driver mutations, it is possible to design combination therapies that can simultaneously address multiple distinct driver effects. The concurrent evaluation of multiple synthetic lethal interactions to discover new combination therapies still remains an underexplored aspect of synthetic lethality principle. Therefore, new technologies that are druggable and can expand the number of targets could potentially have a major impact on drug discovery.

The identification of synthetic lethal effects that are related to various tumor-specific genotypes has been brought to attention by synthetic lethality genotypespecific cell inhibition. For instance, KRAS oncogene mutations are common in various cancers and had been found that ATR or GATA2 transcription factor inhibition is synthetically lethal $[171,172]$. Furthermore, mutations in the p53 gene are one of the most prevalent human tumor-specific genetic changes. Various potential synthetic lethal approaches that focus on p53-mutated 
tumor cells include the key determinant targeting of ATR replication fork stability [111], PI3-kinase signaling cascade components [121], WEE1 protein kinase [123], and CHK1/2 DNA damage checkpoint kinase [140]. Nonetheless, the validation and discovery approaches should emphasize the importance of the identification of synthetic lethal effects with substantial magnitude. Computational analysis improvements and the utilization of better screening technologies could result in novel synthetic lethal interactions which could be applied for better therapeutic targeting.

Recently, nanomedicine had become a promising tool for effective drug delivery, resulting in the reduction of drug dosage, adverse events, and offtarget drug effects [173-175]. The emergence of nanomedicine based on synthetic lethality provides a new path for cancer treatment with enhanced efficacy, increased bioavailability, reduced toxicity, sustained drug release, and positive treatment outcomes [176178]. This concept holds great potential for personalized nanotechnological-based chemotherapeutic treatment to achieve precise delivery of the regimen. Furthermore, the physicochemical properties of the nanoparticle could also be incorporated with DDR inhibitors to further enhance the treatment efficiency [177-179]. However, further preclinical and clinical studies are still required to be able to determine the most effective and clinically relevant treatment. The increase of cancer pathological understandings and targeting receptors, with the correlation of nanoparticle engineering, would undeniably enhance the efficiency of cancer therapy in the future.

\section{Conclusion}

Synthetic lethality is a concept in genetics that have a significant impact on cancer study. The concept of synthetic lethality opens a new path for the development of cancer treatment by targeting the synthetic lethal targets after the cancer-specific mutations are identified. The identification of drug targets and genetic contexts, with increasingly powerful tools and applying synthetic lethality concepts, would definitely be an effective therapeutic option and a transformative opportunity for patients. The incessantly evolving CRISPR screening technology has the potential to address the heterogeneity of tumors in primary drug resistance and genetic mutations in secondary drug resistance. Multiple DDR inhibitors are being developed and tested in various stages, thus meticulous considerations of the mechanisms are needed to maximize the potential of these drugs. The lessons learned from PARP inhibitors have demonstrated that the challenges in managing toxicities resulted from combination therapies, yet clinicians should focus on both monotherapy and combination therapy to establish the finest therapeutic option for cancer patients. Despite the great potential of these methods, several obstacles remain in moving from discovering drug targets to utilizing these effective medicines clinically. Nevertheless, synthetic lethality paved a pathway to a wider range of possibilities with present and future applications.

\section{Abbreviations}

PARP: Poly(ADP-ribose) polymerase; DDR: DNA damage response; ROS: Reactive oxygen species; NRF2: Nuclear factor erythroid 2-related factor 2; HSP90: Heat shock protein 90; CDK1/2: Cyclin-dependent kinase 1/2; PLK1: Polo-like kinase 1; RNAi: RNA interference; CRISPR: Clustered regularly interspaced short palindromic repeats; shRNA: Short hairpin RNA; siRNA: Small interfering RNA; SSB: Single-strand break; DSB: Double-strand break; PFS: Progression-free survival; HR: Homologous recombination; NHEJ: Non-homologous end joining; ATR: Ataxia telangiectasia and rad3 related; DNA-PK: DNA-dependent protein kinase; CHK1/2: Checkpoint kinase 1/2; BER: Base excision repair; APE1: Apurinic/apyrimidinic endonuclease 1; POLB: DNA polymerase b; XRCC1: X-ray repair cross-complementing; PDL1: Programmed death-ligand 1; STING: Stimulator of interferon genes; CXCL10: C-X-C motif chemokine ligand 10; IFN- $\beta$ : Interferon-beta; PD1: Programmed cell death protein 1; CCL5: Chemokine ligand 5; CGAS: Cyclic GMP-AMP synthase; IFN-Y: Interferon-gamma; RPA: Replication protein A; ABCG2: ATP-binding cassette G2; pS6: Phosphorylated ribosomal S6

\section{Acknowledgements}

We would like to thank the authors of the primary studies. The figures in this article were created using Adobe Illustrator, Adobe Photoshop, BioRender, and Microsoft PowerPoint.

\section{Authors' contributions}

WT, SJ, SL, JL, KS, and MC wrote this paper. JC, JH, DM, BZ, and XC reviewed this paper. All authors read and approved the final manuscript.

\section{Funding}

This work was supported by the Opening Fund of Engineering Research Center of Cognitive Healthcare of Zhejiang Province (NO.2018KFJJ09) and the National Natural Science Foundation of China (NO.81827804).

Availability of data and materials

Data sharing not applicable to this article as no datasets were generated or analyzed during the current study.

Ethics approval and consent to participate

Not applicable.

\section{Competing interests}

The authors declare that there are no conflicts of interest.

\section{Author details}

${ }^{1}$ Department of General Surgery, Sir Run-Run Shaw Hospital, Zhejiang University, Hangzhou 310016, China. ${ }^{2}$ School of Medicine, Zhejiang University, Hangzhou 310058, China. ${ }^{3}$ Institute of Pharmaceutics, College of Pharmaceutical Sciences, Zhejiang University, Hangzhou 310058, China. ${ }^{4}$ Key Laboratory of Endoscopic Technique Research of Zhejiang Province, No.3 East Qingchun Road, Hangzhou 310016, China.

Received: 4 June 2020 Accepted: 26 August 2020

Published online: 03 September 2020

\section{References}

1. Hanahan D, Weinberg RA. The hallmarks of cancer. Cell. 2000;100:57-70.

2. Cortes J, Perez-Garcia JM, Llombart-Cussac A, Curigliano G, El Saghir NS, Cardoso F, Barrios CH, Wagle S, Roman J, Harbeck N, et al. Enhancing global access to cancer medicines. CA Cancer J Clin. 2020;70(2):105-24. https://doi. org/10.3322/caac.21597.

3. Siegel RL, Miller KD, Jemal A. Cancer statistics, 2020. CA Cancer J Clin. 2020; 70:7-30.

4. Hyman DM, Taylor BS, Baselga J. Implementing genome-driven oncology. Cell. 2017;168:584-99. 
5. Ashworth A, Lord CJ. Synthetic lethal therapies for cancer: what's next after PARP inhibitors? Nat Rev Clin Oncol. 2018;15:564-76.

6. Mullard A. Synthetic lethality screens point the way to new cancer drug targets. Nat Rev Drug Discov. 2017;16:589-91.

7. Dobzhansky T. Genetics of natural populations; recombination and variability in populations of Drosophila pseudoobscura. Genetics. 1946;31: 269-90

8. Iglehart JD, Silver DP. Synthetic lethality - a new direction in cancer-drug development. N Engl J Med. 2009;361:189-91.

9. O'Neil NJ, Bailey ML, Hieter P. Synthetic lethality and cancer. Nat Rev Genet. 2017;18:613-23

10. Bryant HE, Schultz N, Thomas HD, Parker KM, Flower D, Lopez E, Kyle S, Meuth M, Curtin NJ, Helleday T. Specific killing of BRCA2-deficient tumours with inhibitors of poly(ADP-ribose) polymerase. Nature. 2005;434:913-7.

11. Farmer H, McCabe N, Lord CJ, Tutt AN, Johnson DA, Richardson TB, Santarosa M, Dillon KJ, Hickson I, Knights C, et al. Targeting the DNA repair defect in BRCA mutant cells as a therapeutic strategy. Nature. 2005;434:917-21.

12. Robson M, Im SA, Senkus E, Xu B, Domchek SM, Masuda N, Delaloge S, Li W, Tung N, Armstrong A, et al. Olaparib for metastatic breast cancer in patients with a germline BRCA mutation. N Engl J Med. 2017;377:523-33.

13. Lord CJ, Ashworth A. PARP inhibitors: synthetic lethality in the clinic. Science. 2017;355:1152-8.

14. George A, Kaye S, Banerjee S. Delivering widespread BRCA testing and PARP inhibition to patients with ovarian cancer. Nat Rev Clin Oncol. 2017;14:284-96.

15. Goodall J, Mateo J, Yuan W, Mossop H, Porta N, Miranda S, Perez-Lopez R, Dolling D, Robinson DR, Sandhu S, et al. Circulating cell-free DNA to guide prostate Cancer treatment with PARP inhibition. Cancer Discov. 2017;7: 1006-17.

16. Fong PC, Boss DS, Yap TA, Tutt A, Wu P, Mergui-Roelvink M, Mortimer P Swaisland H, Lau A, O'Connor MJ, et al. Inhibition of poly(ADP-ribose) polymerase in tumors from BRCA mutation carriers. N Engl J Med. 2009;361: 123-34

17. Pantelidou C, Sonzogni O, De Oliveria TM, Mehta AK, Kothari A, Wang D, Visal T, Li MK, Pinto J, Castrillon JA, et al. PARP inhibitor efficacy depends on CD8(+) T-cell recruitment via intratumoral STING pathway activation in BRCA-deficient models of triple-negative breast cancer. Cancer Discov. 2019; 9:722-37.

18. Emerling BM, Hurov JB, Poulogiannis G, Tsukazawa KS, Choo-Wing R, Wulf GM, Bell EL, Shim HS, Lamia KA, Rameh LE, et al. Depletion of a putatively druggable class of phosphatidylinositol kinases inhibits growth of p53-null tumors. Cell. 2013;155:844-57.

19. Bian Y, Kitagawa R, Bansal PK, Fujii Y, Stepanov A, Kitagawa K. Synthetic genetic array screen identifies PP2A as a therapeutic target in Mad2overexpressing tumors. Proc Natl Acad Sci U S A. 2014;111:1628-33.

20. Reid RJ, Du X, Sunjevaric I, Rayannavar V, Dittmar J, Bryant E, Maurer M, Rothstein R. A synthetic dosage lethal genetic interaction between CKS1B and PLK1 is conserved in yeast and human cancer cells. Genetics. 2016;204:807-19.

21. Schopf FH, Biebl MM, Buchner J. The HSP90 chaperone machinery. Nat Rev Mol Cell Biol. 2017;18:345-60

22. Luo M, He H, Kelley MR, Georgiadis MM. Redox regulation of DNA repair: implications for human health and cancer therapeutic development. Antioxid Redox Signal. 2010;12:1247-69.

23. Huber KV, Salah E, Radic B, Gridling M, Elkins JM, Stukalov A, Jemth AS, Gokturk C, Sanjiv K, Stromberg K, et al. Stereospecific targeting of MTH1 by (S)-crizotinib as an anticancer strategy. Nature. 2014;508:222-7.

24. Yu D, Liu Y, Zhou Y, Ruiz-Rodado V, Larion M, Xu G, Yang C. Triptolide suppresses IDH1-mutated malignancy via Nrf2-driven glutathione metabolism. Proc Natl Acad Sci U S A. 2020;117:9964-72.

25. Li J, Csibi A, Yang S, Hoffman GR, Li C, Zhang E, Yu JJ, Blenis J. Synthetic lethality of combined glutaminase and Hsp90 inhibition in mTORC1-driven tumor cells. Proc Natl Acad Sci U S A. 2015;112:E21-9.

26. Pavlova NN, Thompson CB. The emerging hallmarks of cancer metabolism Cell Metab. 2016;23:27-47.

27. Kruiswijk F, Labuschagne CF, Vousden KH. p53 in survival, death and metabolic health: a lifeguard with a licence to kill. Nat Rev Mol Cell Biol. 2015;16:393-405.

28. Liu L, Ulbrich J, Muller J, Wustefeld T, Aeberhard L, Kress TR, Muthalagu N, Rycak $L$, Rudalska $R$, Moll $R$, et al. Deregulated MYC expression induces dependence upon AMPK-related kinase 5. Nature. 2012;483:608-12.

29. Gaude E, Frezza C. Defects in mitochondrial metabolism and cancer. Cancer Metab. 2014;2:10.
30. Ingham M, Schwartz GK. Cell-Cycle Therapeutics come of age. J Clin Oncol. 2017:35:2949-59.

31. McDonald ER 3rd, de Weck A, Schlabach MR, Billy E, Mavrakis KJ, Hoffman GR, Belur D, Castelletti D, Frias E, Gampa K, et al. Project DRIVE: a compendium of cancer dependencies and synthetic lethal relationships uncovered by large-scale, deep RNAi screening. Cell. 2017;170:577-592.e510.

32. Pfister SX, Ashworth A. Marked for death: targeting epigenetic changes in cancer. Nat Rev Drug Discov. 2017;16:241-63.

33. Costanzo M, VanderSluis B, Koch EN, Baryshnikova A, Pons C, Tan G, Wang W, Usaj M, Hanchard J, Lee SD, et al. A global genetic interaction network maps a wiring diagram of cellular function. Science. 2016;353.

34. Lissanu Deribe Y, Sun Y, Terranova C, Khan F, Martinez-Ledesma J, Gay J, Gao G, Mullinax RA, Khor T, Feng N, et al. Mutations in the SWI/SNF complex induce a targetable dependence on oxidative phosphorylation in lung cancer. Nat Med. 2018:24:1047-57.

35. Perkhofer L, Schmitt A, Romero Carrasco MC, Ihle M, Hampp S, Ruess DA, Hessmann E, Russell R, Lechel A, Azoitei N, et al. ATM deficiency generating genomic instability sensitizes pancreatic ductal adenocarcinoma cells to therapy-induced DNA damage. Cancer Res. 2017:77:5576-90.

36. Kwok M, Davies $N$, Agathanggelou A, Smith E, Oldreive C, Petermann E, Stewart G, Brown J, Lau A, Pratt G, et al. ATR inhibition induces synthetic lethality and overcomes chemoresistance in TP53- or ATM-defective chronic lymphocytic leukemia cells. Blood. 2016;127:582-95.

37. Kwok M, Davies N, Agathanggelou A, Smith E, Petermann E, Yates E, Brown J, Lau A, Stankovic T. Synthetic lethality in chronic lymphocytic leukaemia with DNA damage response defects by targeting the ATR pathway. Lancet. 2015;385(Suppl 1):S58

38. Giovannini S, Weller MC, Repmann S, Moch H, Jiricny J. Synthetic lethality between BRCA1 deficiency and poly(ADP-ribose) polymerase inhibition is modulated by processing of endogenous oxidative DNA damage. Nucleic Acids Res. 2019;47:9132-43.

39. Ding X, Ray Chaudhuri A, Callen E, Pang Y, Biswas K, Klarmann KD, Martin BK, Burkett S, Cleveland L, Stauffer S, et al. Synthetic viability by BRCA2 and PARP1/ARTD1 deficiencies. Nat Commun. 2016;7:12425.

40. Ikui AE, Rossio V, Schroeder L, Yoshida S. A yeast GSK-3 kinase Mck1 promotes Cdc6 degradation to inhibit DNA re-replication. PLoS Genet. 2012;8:e1003099.

41. Steckel M, Molina-Arcas M, Weigelt B, Marani M, Warne PH, Kuznetsov H, Kelly G, Saunders B, Howell M, Downward J, Hancock DC. Determination of synthetic lethal interactions in KRAS oncogene-dependent cancer cells reveals novel therapeutic targeting strategies. Cell Res. 2012;22:1227-45.

42. Costa-Cabral S, Brough R, Konde A, Aarts M, Campbell J, Marinari E, Riffell J, Bardelli A, Torrance C, Lord CJ, Ashworth A. CDK1 Is a synthetic lethal target for KRAS mutant tumours. PLoS One. 2016;11:e0149099.

43. Asghar U, Witkiewicz AK, Turner NC, Knudsen ES. The history and future of targeting cyclin-dependent kinases in cancer therapy. Nat Rev Drug Discov. 2015;14:130-46.

44. Nekova TS, Kneitz S, Einsele H, Bargou R, Stuhler G. Silencing of CDK2, but not CDK1, separates mitogenic from anti-apoptotic signaling, sensitizing p53 defective cells for synthetic lethality. Cell Cycle. 2016;15:3203-9.

45. Leonardi M, Perna E, Tronnolone S, Colecchia D, Chiariello M. Activated kinase screening identifies the IKBKE oncogene as a positive regulator of autophagy. Autophagy. 2019;15:312-26.

46. Meng Y, Chen CW, Yung MMH, Sun W, Sun J, Li Z, Li J, Li Z, Zhou W, Liu SS, et al. DUOXA1-mediated ROS production promotes cisplatin resistance by activating ATR-Chk1 pathway in ovarian cancer. Cancer Lett. 2018;428:104-16.

47. Gadhikar MA, Sciuto MR, Alves MV, Pickering CR, Osman AA, Neskey DM, Zhao M, Fitzgerald AL, Myers JN, Frederick MJ. Chk1/2 inhibition overcomes the cisplatin resistance of head and neck cancer cells secondary to the loss of functional p53. Mol Cancer Ther. 2013;12:1860-73.

48. Shen S, Mao CQ, Yang XZ, Du XJ, Liu Y, Zhu YH, Wang J. Cationic lipidassisted polymeric nanoparticle mediated GATA2 siRNA delivery for synthetic lethal therapy of KRAS mutant non-small-cell lung carcinoma. Mol Pharm. 2014;11:2612-22.

49. Drosten M, Barbacid M. Targeting the MAPK pathway in KRAS-driven tumors. Cancer Cell. 2020;37:543-50.

50. Hu K, Li K, LV J, Feng J, Chen J, Wu H, Cheng F, Jiang W, Wang J, Pei H, et al. Suppression of the SLC7A11/glutathione axis causes synthetic lethality in KRAS-mutant lung adenocarcinoma. J Clin Invest. 2020;130:1752-66.

51. Ying S, Hamdy FC, Helleday T. Mre11-dependent degradation of stalled DNA replication forks is prevented by BRCA2 and PARP1. Cancer Res. 2012; 72:2814-21. 
52. Baluapuri A, Wolf E, Eilers M. Target gene-independent functions of MYC oncoproteins. Nat Rev Mol Cell Biol. 2020;21:255-67.

53. Wang J, Jiang J, Chen H, Wang L, Guo H, Yang L, Xiao D, Qing G, Liu H. FDA-approved drug screen identifies proteasome as a synthetic lethal target in MYC-driven neuroblastoma. Oncogene. 2019;38:6737-51.

54. Kim JH, Penson AV, Taylor BS, Petrini JHJ. Nbn-Mre11 interaction is required for tumor suppression and genomic integrity. Proc Natl Acad Sci U S A. 2019;116:15178-83.

55. Baldwin A, Grueneberg DA, Hellner K, Sawyer J, Grace M, Li W, Harlow E, Munger K. Kinase requirements in human cells: $V$. Synthetic lethal interactions between p53 and the protein kinases SGK2 and PAK3. Proc Natl Acad Sci U S A. 2010;107:12463-8.

56. Gogola E, Duarte AA, de Ruiter JR, Wiegant WW, Schmid JA, de Bruijn R, James DI, Guerrero Llobet S, Vis DJ, Annunziato S, et al. Selective loss of PARG restores PARylation and counteracts PARP inhibitor-mediated synthetic lethality. Cancer Cell. 2018;33:1078-1093.e1012.

57. Wang J, Hu K, Guo J, Cheng F, Lv J, Jiang W, Lu W, Liu J, Pang X, Liu M. Suppression of KRas-mutant cancer through the combined inhibition of KRAS with PLK1 and ROCK. Nat Commun. 2016;7:11363.

58. Al-Ahmadie H, Iyer G, Hohl M, Asthana S, Inagaki A, Schultz N, Hanrahan AJ, Scott SN, Brannon AR, McDermott GC, et al. Synthetic lethality in ATMdeficient RAD50-mutant tumors underlies outlier response to cancer therapy. Cancer Discov. 2014;4:1014-21.

59. Huang TH, Fowler F, Chen CC, Shen ZJ, Sleckman B, Tyler JK. The histone chaperones ASF1 and CAF-1 promote MMS22L-TONSL-mediated Rad51 loading onto ssDNA during homologous recombination in human cells. Mol Cell. 2018;69:879-892.e875.

60. Brown CJ, Lain S, Verma CS, Fersht AR, Lane DP. Awakening guardian angels: drugging the p53 pathway. Nat Rev Cancer. 2009;9:862-73.

61. Zhao Y, Ding L, Wang D, Ye Z, He Y, Ma L, Zhu R, Pan Y, Wu Q, Pang K, et al. EZH2 cooperates with gain-of-function p53 mutants to promote cancer growth and metastasis. Embo j. 2019;38.

62. Tarsounas M, Sung P. The antitumorigenic roles of BRCA1-BARD1 in DNA repair and replication. Nat Rev Mol Cell Biol. 2020;21:284-99.

63. Parvin S, Ramirez-Labrada A, Aumann S, Lu X, Weich N, Santiago G, Cortizas EM, Sharabi E, Zhang Y, Sanchez-Garcia I, et al. LMO2 confers synthetic lethality to PARP inhibition in DLBCL. Cancer Cell. 2019;36:237-249.e236.

64. Bukhari AB, Lewis CW, Pearce JJ, Luong D, Chan GK, Gamper AM. Inhibiting Wee1 and ATR kinases produces tumor-selective synthetic lethality and suppresses metastasis. J Clin Invest. 2019;129:1329-44.

65. Wolter K, Zender L. Therapy-induced senescence-an induced synthetic lethality in liver cancer? Nat Rev Gastroenterol Hepatol. 2020;17:135-6.

66. Frey N, Venturelli S, Zender L, Bitzer M. Cellular senescence in gastrointestinal diseases: from pathogenesis to therapeutics. Nat Rev Gastroenterol Hepatol. 2018;15:81-95.

67. Dörr JR, Yu Y, Milanovic M, Beuster G, Zasada C, Däbritz JH, Lisec J, Lenze D, Gerhardt A, Schleicher K, et al. Synthetic lethal metabolic targeting of cellular senescence in cancer therapy. Nature. 2013;501:421-5.

68. Fleury H, Malaquin N, Tu V, Gilbert S, Martinez A, Olivier MA, Sauriol A, Communal L, Leclerc-Desaulniers K, Carmona E, et al. Exploiting interconnected synthetic lethal interactions between PARP inhibition and cancer cell reversible senescence. Nat Commun. 2019;10:2556.

69. Hartwell LH, Szankasi P, Roberts CJ, Murray AW, Friend SH. Integrating genetic approaches into the discovery of anticancer drugs. Science. 1997; 278:1064-8.

70. Adames NR, Gallegos JE, Peccoud J. Yeast genetic interaction screens in the age of CRISPR/Cas. Curr Genet. 2019;65:307-27.

71. Yeh CS, Wang Z, Miao F, Ma H, Kao CT, Hsu TS, Yu JH, Hung ET, Lin CC, Kuan $C Y$, et al. A novel synthetic-genetic-array-based yeast one-hybrid system for high discovery rate and short processing time. Genome Res. 2019;29:1343-51

72. Pan X, Ye P, Yuan DS, Wang X, Bader JS, Boeke JD. A DNA integrity network in the yeast Saccharomyces cerevisiae. Cell. 2006;124:1069-81.

73. Gu Y, Wang R, Han Y, Zhou W, Zhao Z, Chen T, Zhang Y, Peng F, Liang H, Qi L, et al. A landscape of synthetic viable interactions in cancer. Brief Bioinform. 2018;19:644-55.

74. Liu L, Chen X, Hu C, Zhang D, Shao Z, Jin Q, Yang J, Xie H, Liu B, Hu M, Ke K. Synthetic lethality-based identification of targets for anticancer drugs in the human signaling network. Sci Rep. 2018;8:8440.

75. Setten RL, Rossi JJ, Han SP. The current state and future directions of RNAibased therapeutics. Nat Rev Drug Discov. 2019;18:421-46.
76. Stojic L, Lun ATL, Mascalchi P, Ernst C, Redmond AM, Mangei J, Barr AR, Bousgouni V, Bakal C, Marioni JC, et al. A high-content RNAi screen reveals multiple roles for long noncoding RNAs in cell division. Nat Commun. 2020; 11:1851.

77. Champagne J, Linares LK, Maurel B, Zampieri A, Moreno M, Fuentes I, Dubois E, Severac D, Decorsière A, Bienvenu F. TAG-RNAi overcomes offtarget effects in cancer models. Oncogene. 2020;39:935-45.

78. Pelossof R, Fairchild L, Huang CH, Widmer C, Sreedharan VT, Sinha N, Lai DY, Guan Y, Premsrirut PK, Tschaharganeh DF, et al. Prediction of potent shRNAs with a sequential classification algorithm. Nat Biotechnol. 2017;35:350-3.

79. Evers B, Jastrzebski K, Heijmans JP, Grernrum W, Beijersbergen RL, Bernards R. CRISPR knockout screening outperforms shRNA and CRISPRi in identifying essential genes. Nat Biotechnol. 2016;34:631-3.

80. Morgens DW, Deans RM, Li A, Bassik MC. Systematic comparison of CRISPR/ Cas9 and RNAi screens for essential genes. Nat Biotechnol. 2016;34:634-6.

81. Behan FM, lorio F, Picco G, Goncalves E, Beaver CM, Migliardi G, Santos R, Rao Y, Sassi F, Pinnelli M, et al. Prioritization of cancer therapeutic targets using CRISPR-Cas9 screens. Nature. 2019;568:511-6.

82. Carbajosa S, Pansa MF, Paviolo NS, Castellaro AM, Andino DL, Nigra AD, Garcia IA, Racca AC, Rodriguez-Berdini L, Angiolini V, et al. Polo-like kinase 1 inhibition as a therapeutic approach to selectively target BRCA1-deficient cancer cells by synthetic lethality induction. Clin Cancer Res. 2019;25:4049-62.

83. Dhanjal JK, Radhakrishnan N, Sundar D. Identifying synthetic lethal targets using CRISPR/Cas9 system. Methods. 2017;131:66-73.

84. Alkan F, Erten C. SiPAN: simultaneous prediction and alignment of proteinprotein interaction networks. Bioinformatics. 2015;31:2356-63.

85. Fan J, Cannistra A, Fried I, Lim T, Schaffner T, Crovella M, Hescott B, Leiserson MDM. Functional protein representations from biological networks enable diverse cross-species inference. Nucleic Acids Res. 2019;47:e51.

86. Benard B, Gentles AJ, Kohnke T, Majeti R, Thomas D. Data mining for mutationspecific targets in acute myeloid leukemia. Leukemia. 2019;33:826-43.

87. Plummer R, Lorigan P, Steven N, Scott L, Middleton MR, Wilson RH, Mulligan E, Curtin N, Wang D, Dewji R, et al. A phase II study of the potent PARP inhibitor, Rucaparib (PF-01367338, AG014699), with temozolomide in patients with metastatic melanoma demonstrating evidence of chemopotentiation. Cancer Chemother Pharmacol. 2013:71:1191-9.

88. Audeh MW, Carmichael J, Penson RT, Friedlander M, Powell B, Bell-McGuinn KM, Scott C, Weitzel JN, Oaknin A, Loman N, et al. Oral poly(ADP-ribose) polymerase inhibitor olaparib in patients with BRCA1 or BRCA2 mutations and recurrent ovarian cancer: a proof-of-concept trial. Lancet. 2010;376:245-51.

89. Moore K, Colombo N, Scambia G, Kim BG, Oaknin A, Friedlander M, Lisyanskaya A, Floquet A, Leary A, Sonke GS, et al. Maintenance olaparib in patients with newly diagnosed advanced ovarian cancer. N Engl J Med. 2018:379:2495-505.

90. Tutt A, Robson M, Garber JE, Domchek SM, Audeh MW, Weitzel JN, Friedlander M, Arun B, Loman N, Schmutzler RK, et al. Oral poly(ADP-ribose) polymerase inhibitor olaparib in patients with BRCA1 or BRCA2 mutations and advanced breast cancer: a proof-of-concept trial. Lancet. 2010;376:235-44.

91. Golan T, Hammel P, Reni M, Van Cutsem E, Macarulla T, Hall MJ, Park JO, Hochhauser D, Arnold D, Oh DY, et al. Maintenance Olaparib for germline BRCA-mutated metastatic pancreatic cancer. N Engl J Med. 2019;381:317-27.

92. Mateo J, Porta N, Bianchini D, McGovern U, Elliott T, Jones R, Syndikus I, Ralph C, Jain S, Varughese M, et al. Olaparib in patients with metastatic castration-resistant prostate cancer with DNA repair gene aberrations (TOPARP-B): a multicentre, open-label, randomised, phase 2 trial. Lancet Oncol. 2020;21:162-74.

93. Kaufman B, Shapira-Frommer R, Schmutzler RK, Audeh MW, Friedlander M, Balmana J, Mitchell G, Fried G, Stemmer SM, Hubert A, et al. Olaparib monotherapy in patients with advanced cancer and a germline BRCA1/2 mutation. J Clin Oncol. 2015:33:244-50.

94. Kim G, Ison G, McKee AE, Zhang H, Tang S, Gwise T, Sridhara R, Lee E, Tzou A, Philip R, et al. FDA approval summary: Olaparib monotherapy in patients with deleterious germline BRCA-mutated advanced ovarian cancer treated with three or more lines of chemotherapy. Clin Cancer Res. 2015;21:4257-61.

95. Ison G, Howie L, Amiri-Kordestani L, Zhang L, Tang S, Sridhara R, Pierre V, Charlab R, Ramamoorthy A, Song P, et al. FDA approval summary: Niraparib for the maintenance treatment of patients with recurrent ovarian cancer in response to platinum-based chemotherapy. Clin Cancer Res. 2018;24:4066-71.

96. Sandhu SK, Schelman WR, Wilding G, Moreno V, Baird RD, Miranda S, Hylands L, Riisnaes R, Forster M, Omlin A, et al, The poly(ADP-ribose) polymerase inhibitor niraparib (MK4827) in BRCA mutation carriers and 
patients with sporadic cancer: a phase 1 dose-escalation trial. Lancet Oncol. 2013;14:882-92.

97. Mirza MR, Monk BJ, Herrstedt J, Oza AM, Mahner S, Redondo A, Fabbro M, Ledermann JA, Lorusso D, Vergote I, et al. Niraparib Maintenance therapy in platinum-sensitive, recurrent ovarian cancer. N Engl J Med. 2016;375:2154-64.

98. Gonzalez Martin A. Progress in PARP inhibitors beyond BRCA mutant recurrent ovarian cancer? Lancet Oncol. 2017;18:8-9.

99. Swisher EM, Lin KK, Oza AM, Scott CL, Giordano H, Sun J, Konecny GE, Coleman RL, Tinker AV, O'Malley DM, et al. Rucaparib in relapsed, platinumsensitive high-grade ovarian carcinoma (ARIEL2 Part 1): an international, multicentre, open-label, phase 2 trial. Lancet Oncol. 2017;18:75-87.

100. Coleman RL, Oza AM, Lorusso D, Aghajanian C, Oaknin A, Dean A, Colombo N, Weberpals Jl, Clamp A, Scambia G, et al. Rucaparib maintenance treatment for recurrent ovarian carcinoma after response to platinum therapy (ARIEL3): a randomised, double-blind, placebo-controlled, phase 3 trial. Lancet. 2017;390:1949-61.

101. Hoy SM. Talazoparib: first global approval. Drugs. 2018;78:1939-46.

102. de Bono J, Ramanathan RK, Mina L, Chugh R, Glaspy J, Rafii S, Kaye S, Sachdev J, Heymach J, Smith DC, et al. Phase I, dose-escalation, two-part trial of the PARP inhibitor talazoparib in patients with advanced germline BRCA1/2 mutations and selected sporadic cancers. Cancer Discov. 2017;7: $620-9$.

103. Turner NC, Telli ML, Rugo HS, Mailliez A, Ettl J, Grischke EM, Mina LA, Balmana J, Fasching PA, Hurvitz SA, et al. A phase II study of talazoparib after platinum or cytotoxic nonplatinum regimens in patients with advanced breast cancer and germline BRCA1/2 mutations (ABRAZO). Clin Cancer Res. 2019;25:2717-24.

104. Litton JK, Rugo HS, Ettl J, Hurvitz SA, Goncalves A, Lee KH, Fehrenbacher L, Yerushalmi R, Mina LA, Martin M, et al. Talazoparib in patients with advanced breast cancer and a germline BRCA mutation. N Engl J Med. 2018;379:753-63.

105. Lecona E, Fernandez-Capetillo O. Targeting ATR in cancer. Nat Rev Cancer. 2018;18:586-95.

106. Menolfi D, Jiang W, Lee BJ, Moiseeva T, Shao Z, Estes V, Frattini MG, Bakkenist CJ, Zha S. Kinase-dead ATR differs from ATR loss by limiting the dynamic exchange of ATR and RPA. Nat Commun. 2018:9:5351.

107. Ha GH, Ji JH, Chae S, Park J, Kim S, Lee JK, Kim Y, Min S, Park JM, Kang TH, et al. Pellino1 regulates reversible ATM activation via NBS1 ubiquitination at DNA double-strand breaks. Nat Commun. 2019;10:1577.

108. Bradbury A, Hall S, Curtin N, Drew Y. Targeting ATR as cancer therapy: a new era for synthetic lethality and synergistic combinations? Pharmacol Ther. 2020;207:107450

109. Kumar A, Mazzanti M, Mistrik M, Kosar M, Beznoussenko GV, Mironov AA, Garrè M, Parazzoli D, Shivashankar GV, Scita G, et al. ATR mediates a checkpoint at the nuclear envelope in response to mechanical stress. Cell. 2014;158:633-46.

110. Brown JS, O'Carrigan B, Jackson SP, Yap TA. Targeting DNA repair in cancer: beyond PARP inhibitors. Cancer Discov. 2017;7:20-37.

111. Gorecki L, Andrs M, Rezacova M, Korabecny J. Discovery of ATR kinase inhibitor berzosertib (VX-970, M6620): Clinical candidate for cancer therapy. Pharmacol Ther. 2020;210:107518. https://doi.org/10.1016/.jpharmthera.2020. 107518. Epub 2020 Feb 26.

112. Thomas A, Redon CE, Sciuto L, Padiernos E, Ji J, Lee MJ, Yuno A, Lee S, Zhang Y, Tran L, et al. Phase I study of ATR inhibitor M6620 in combination with Topotecan in patients with advanced solid tumors. J Clin Oncol. 2018; 36:1594-602.

113. Dillon MT, Boylan Z, Smith D, Guevara J, Mohammed K, Peckitt C, Saunders M, Banerii U, Clack G, Smith SA, et al. PATRIOT: A phase I study to assess the tolerability, safety and biological effects of a specific ataxia telangiectasia and Rad3-related (ATR) inhibitor (AZD6738) as a single agent and in combination with palliative radiation therapy in patients with solid tumours. Clin Transl Radiat Oncol. 2018:12:16-20.

114. Kantidze OL, Velichko AK, Luzhin AV, Petrova NV, Razin SV. Synthetically lethal interactions of ATM, ATR, and DNA-PKcs. Trends Cancer. 2018:4:75568.

115. Ochi T, Blackford AN, Coates J, Jhujh S, Mehmood S, Tamura N, Travers J, Wu Q, Draviam VM, Robinson CV, et al: DNA repair. PAXX, a paralog of XRCC4 and XLF, interacts with Ku to promote DNA double-strand break repair. Science 2015, 347:185-188.

116. Albarakati N, Abdel-Fatah TM, Doherty R, Russell R, Agarwal D, Moseley P, Perry C, Arora A, Alsubhi N, Seedhouse C, et al. Targeting BRCA1-BER deficient breast cancer by ATM or DNA-PKcs blockade either alone or in combination with cisplatin for personalized therapy. Mol Oncol. 2015;9:20417.

117. Caldecott KW. Single-strand break repair and genetic disease. Nat Rev Genet. 2008;9:619-31.

118. An J, Yang DY, Xu QZ, Zhang SM, Huo YY, Shang ZF, Wang Y, Wu DC, Zhou PK. DNA-dependent protein kinase catalytic subunit modulates the stability of c-Myc oncoprotein. Mol Cancer. 2008;7:32.

119. Mortensen DS, Perrin-Ninkovic SM, Shevlin G, Elsner J, Zhao J, Whitefield B, Tehrani L, Sapienza J, Riggs JR, Parnes JS, et al. Optimization of a series of triazole containing mammalian target of rapamycin (mTOR) kinase inhibitors and the discovery of CC-115. J Med Chem. 2015;58:5599-608.

120. Munster PN, Mahipal A, Nemunaitis JJ, Mita MM, Paz-Ares LG, Massard C, Mikkelsen T, Cruz C, Rathkopf DE, Blumenschein GR, et al. Phase I trial of a dual TOR kinase and DNA-PK inhibitor (CC-115) in advanced solid and hematologic cancers. J Clin Oncol. 2016;34:2505.

121. Fok JHL, Ramos-Montoya A, Vazquez-Chantada M, Wijnhoven PWG, Follia V, James N, Farrington PM, Karmokar A, Willis SE, Cairns J, et al. AZD7648 is a potent and selective DNA-PK inhibitor that enhances radiation, chemotherapy and olaparib activity. Nat Commun. 2019;10:5065.

122. Goldberg FW, Finlay MRV, Ting AKT, Beattie D, Lamont GM, Fallan C, Wrigley GL, Schimpl M, Howard MR, Williamson B, et al. The discovery of 7-methyl2-[(7-methyl[1,2,4]triazolo[1,5-a]pyridin-6-yl)amino]-9-(tetrahydro-2H-p yran-4yl)-7,9-dihydro-8H-purin-8-one (AZD7648), a potent and selective DNADependent protein kinase (DNA-PK) Inhibitor. J Med Chem. 2020;63(7): 3461-71. https://doi.org/10.1021/acs.jmedchem.9b01684.

123. Pfister SX, Markkanen E, Jiang Y, Sarkar S, Woodcock M, Orlando G, Mavrommati I, Pai CC, Zalmas LP, Drobnitzky N, et al. Inhibiting WEE1 selectively kills histone H3K36me3-deficient cancers by dNTP starvation. Cancer Cell. 2015;28:557-68.

124. Diab A, Kao M, Kehrli K, Kim HY, Sidorova J, Mendez E. Multiple defects sensitize p53-deficient head and neck cancer cells to the WEE1 kinase inhibition. Mol Cancer Res. 2019;17:1115-28.

125. Meng X, Bi J, Li Y, Yang S, Zhang Y, Li M, Liu H, Li Y, McDonald ME, Thie KW, et al. AZD1775 increases sensitivity to olaparib and gemcitabine in cancer cells with p53 mutations. Cancers (Basel). 2018;10(5):149. https://doi. org/10.3390/cancers 10050149.

126. Liang J, Zhao H, Diplas BH, Liu S, Liu J, Wang D, Lu Y, Zhu Q, Wu J, Wang W, et al. Genome-wide CRISPR-Cas9 screen reveals selective vulnerability of ATRX-mutant cancers to WEE1 inhibition. Cancer Res. 2020;80:510-23.

127. Aarts M, Sharpe R, Garcia-Murillas I, Gevensleben H, Hurd MS, Shumway SD, Toniatti C, Ashworth A, Turner NC. Forced mitotic entry of S-phase cells as a therapeutic strategy induced by inhibition of WEE1. Cancer Discov. 2012;2: 524-39.

128. Bridges KA, Hirai H, Buser CA, Brooks C, Liu H, Buchholz TA, Molkentine JM, Mason KA, Meyn RE. MK-1775, a novel Wee1 kinase inhibitor, radiosensitizes p53-defective human tumor cells. Clin Cancer Res. 2011;17:5638-48.

129. Do K, Wilsker D, Ji J, Zlott J, Freshwater T, Kinders RJ, Collins J, Chen AP, Doroshow JH, Kummar S. Phase I study of single-agent AZD1775 (MK-1775), a Wee1 kinase inhibitor, in patients with refractory solid tumors. J Clin Oncol. 2015;33:3409-15.

130. Leijen S, van Geel RM, Pavlick AC, Tibes R, Rosen L, Razak AR, Lam R, Demuth T, Rose S, Lee MA, et al. Phase I study evaluating WEE1 Inhibitor AZD1775 As monotherapy and in combination with gemcitabine, cisplatin, or carboplatin in patients with advanced solid tumors. J Clin Oncol. 2016;34: $4371-80$.

131. Leijen S, van Geel RM, Sonke GS, de Jong D, Rosenberg EH, Marchetti S, Pluim D, van Werkhoven E, Rose S, Lee MA, et al. Phase II study of WEE1 inhibitor AZD1775 plus carboplatin in patients with TP53-mutated ovarian cancer refractory or resistant to first-line therapy within 3 months. J Clin Oncol. 2016;34:4354-61.

132. Dietlein F, Kalb B, Jokic M, Noll EM, Strong A, Tharun L, Ozretić L, Künstlinger $H$, Kambartel K, Randerath WJ, et al. A synergistic interaction between Chk1- and MK2 inhibitors in KRAS-mutant cancer. Cell. 2015;162:146-59.

133. Goto H, Natsume T, Kanemaki MT, Kaito A, Wang S, Gabazza EC, Inagaki M, Mizoguchi A. Chk1-mediated Cdc25A degradation as a critical mechanism for normal cell cycle progression. J Cell Sci. 2019;132.

134. Rogers RF, Walton MI, Cherry DL, Collins I, Clarke PA, Garrett MD, Workman $P$. CHK1 inhibition is synthetically lethal with loss of B-family DNA polymerase function in human lung and colorectal cancer cells. Cancer Res. 2020;80:1735-47. 
135. Gourley C, Balmaña J, Ledermann JA, Serra V, Dent R, Loibl S, PujadeLauraine E, Boulton SJ. Moving from poly (ADP-Ribose) polymerase inhibition to targeting DNA repair and DNA damage response in cancer therapy. J Clin Oncol. 2019;37:2257-69.

136. Qiu Z, Oleinick NL, Zhang J. ATR/CHK1 inhibitors and cancer therapy. Radiother Oncol. 2018;126:450-64.

137. Sen T, Della Corte CM, Milutinovic S, Cardnell RJ, Diao L, Ramkumar K, Gay CM, Stewart CA, Fan Y, Shen L, et al. Combination treatment of the oral CHK1 inhibitor, SRA737, and Low-dose gemcitabine enhances the effect of programmed death ligand 1 blockade by modulating the immune microenvironment in SCLC. J Thorac Oncol. 2019;14:2152-63.

138. Hong D, Infante J, Janku F, Jones S, Nguyen LM, Burris $H$, Naing A, Bauer TM, Piha-Paul S, Johnson FM, et al. Phase I study of LY2606368, a checkpoint kinase 1 inhibitor, in patients with advanced cancer. J Clin Oncol. 2016;34:1764-71.

139. Hong DS, Moore K, Patel M, Grant SC, Burris HA 3rd, William WN Jr, Jones S, Meric-Bernstam F, Infante J, Golden L, et al. Evaluation of prexasertib, a checkpoint kinase 1 inhibitor, in a phase lb study of patients with squamous cell carcinoma. Clin Cancer Res. 2018:24:3263-72.

140. Lee JM, Nair J, Zimmer A, Lipkowitz S, Annunziata CM, Merino MJ, Swisher EM, Harrell MI, Trepel JB, Lee MJ, et al. Prexasertib, a cell cycle checkpoint kinase 1 and 2 inhibitor, in BRCA wild-type recurrent high-grade serous ovarian cancer: a first-in-class proof-of-concept phase 2 study. Lancet Oncol. 2018;19:207-15

141. Matsuno Y, Hyodo M, Fujimori H, Shimizu A, Yoshioka Kl. Sensitization of cancer cells to radiation and topoisomerase I inhibitor camptothecin using inhibitors of PARP and other signaling molecules. Cancers (Basel). 2018;10(10):364. https://doi.org/10.3390/cancers10100364.

142. Drean A, Lord CJ, Ashworth A. PARP inhibitor combination therapy. Crit Rev Oncol Hematol. 2016;108:73-85.

143. Lu Y, Liu Y, Pang Y, Pacak K, Yang C. Double-barreled gun: combination of PARP inhibitor with conventional chemotherapy. Pharmacol Ther. 2018;188: $168-75$

144. Han HS, Diéras V, Robson M, Palácová M, Marcom PK, Jager A, Bondarenko I, Citrin D, Campone M, Telli ML, et al. Veliparib with temozolomide or carboplatin/paclitaxel versus placebo with carboplatin/paclitaxel in patients with BRCA1/2 locally recurrent/metastatic breast cancer: randomized phase II study. Ann Oncol. 2018;29:154-61.

145. Li A, Yi M, Qin S, Chu Q, Luo S, Wu K. Prospects for combining immune checkpoint blockade with PARP inhibition. J Hematol Oncol. 2019:12.98.

146. Färkkilä A, Gulhan DC, Casado J, Jacobson CA, Nguyen H, Kochupurakkal B, Maliga Z, Yapp C, Chen YA, Schapiro D, et al. Immunogenomic profiling determines responses to combined PARP and PD-1 inhibition in ovarian cancer. Nat Commun. 2020;11:1459

147. Ding L, Kim HJ, Wang Q, Kearns M, Jiang T, Ohlson CE, Li BB, Xie S, Liu JF, Stover EH, et al. PARP inhibition elicits STING-dependent antitumor immunity in Brca1-deficient ovarian cancer. Cell Rep. 2018;25:2972-2980. e2975.

148. Shen J, Zhao W, Ju Z, Wang L, Peng Y, Labrie M, Yap TA, Mills GB, Peng G. PARPi triggers the STING-Dependent immune response and enhances the therapeutic efficacy of immune checkpoint blockade independent of BRCAness. Cancer Res. 2019;79:311-9.

149. Zimmer AS, Nichols E, Cimino-Mathews A, Peer C, Cao L, Lee MJ, Kohn EC, Annunziata CM, Lipkowitz S, Trepel JB, et al. A phase I study of the PD-L1 inhibitor, durvalumab, in combination with a PARP inhibitor, olaparib, and a VEGFR1-3 inhibitor, cediranib, in recurrent women's cancers with biomarker analyses. J Immunother Cancer. 2019;7:197.

150. Sheng H, Huang Y, Xiao Y, Zhu Z, Shen M, Zhou P, Guo Z, Wang J, Wang H, Dai W, et al. ATR inhibitor AZD6738 enhances the antitumor activity of radiotherapy and immune checkpoint inhibitors by potentiating the tumor immune microenvironment in hepatocellular carcinoma. J Immunother Cancer. 2020;8(1):e000340. https://doi.org/10.1136/jitc-2019-000340.

151. Patel P, Sun L, Robbins Y, Clavijo PE, Friedman J, Silvin C, Van Waes C, Cook J, Mitchell J, Allen C. Enhancing direct cytotoxicity and response to immune checkpoint blockade following ionizing radiation with Wee1 kinase inhibition. Oncoimmunology. 2019;8:e1638207.

152. Ryan CJ, Bajrami I, Lord CJ. Synthetic lethality and cancer-penetrance as the major barrier. Trends Cancer. 2018:4:671-83.

153. Bitler BG, Watson ZL, Wheeler LJ, Behbakht K. PARP inhibitors: clinical utility and possibilities of overcoming resistance. Gynecol Oncol. 2017;147:695704.
154. Lee SB, Segura-Bayona S, Villamor-Paya M, Saredi G, Todd MAM, Attolini CS, Chang TY, Stracker TH, Groth A. Tousled-like kinases stabilize replication forks and show synthetic lethality with checkpoint and PARP inhibitors. Sci Adv. 2018:4:eaat4985.

155. Colicchia V, Petroni M, Guarguaglini G, Sardina F, Sahun-Roncero M, Carbonari M, Ricci B, Heil C, Capalbo C, Belardinilli F, et al. PARP inhibitors enhance replication stress and cause mitotic catastrophe in MYCNdependent neuroblastoma. Oncogene. 2017;36:4682-91.

156. Kondrashova O, Nguyen M, Shield-Artin K, Tinker AV, Teng NNH, Harrell MI, Kuiper MJ, Ho GY, Barker H, Jasin M, et al. Secondary somatic mutations restoring RAD51C and RAD51D associated with acquired resistance to the PARP inhibitor rucaparib in high-grade ovarian carcinoma. Cancer Discov. 2017:7:984-98.

157. Quigley D, Alumkal JJ, Wyatt AW, Kothari V, Foye A, Lloyd P, Aggarwal R, Kim W, Lu E, Schwartzman J, et al. Analysis of circulating cell-free DNA identifies multiclonal heterogeneity of BRCA2 reversion mutations associated with resistance to PARP inhibitors. Cancer Discov. 2017;7:999-1005.

158. Pettitt SJ, Krastev DB, Brandsma I, Drean A, Song F, Aleksandrov R, Harrell Ml, Menon M, Brough R, Campbell J, et al. Genome-wide and high-density CRISPR-Cas9 screens identify point mutations in PARP1 causing PARP inhibitor resistance. Nat Commun. 2018;9:1849.

159. Henssen AG, Reed C, Jiang E, Garcia HD, von Stebut J, MacArthur IC, Hundsdoerfer P, Kim JH, de Stanchina E, Kuwahara $Y$, et al. Therapeutic targeting of PGBD5-induced DNA repair dependency in pediatric solid tumors. Sci Transl Med. 2017;9(414):eaam9078. https://doi.org/10.1126/ scitranslmed.aam9078.

160. Ruiz S, Mayor-Ruiz C, Lafarga V, Murga M, Vega-Sendino M, Ortega S, Fernandez-Capetillo O. A genome-wide CRISPR screen identifies CDC25A as a determinant of sensitivity to ATR inhibitors. Mol Cell. 2016;62:307-13.

161. Dietlein F, Thelen $L$, Jokic M, Jachimowicz RD, Ivan L, Knittel G, Leeser U, van Oers J, Edelmann W, Heukamp LC, Reinhardt HC. A functional cancer genomics screen identifies a druggable synthetic lethal interaction between MSH3 and PRKDC. Cancer Discov. 2014;4:592-605.

162. Hinrichsen I, Ackermann A, Düding T, Graband A, Filmann N, Plotz G, Zeuzem S, Brieger A. Loss of MLH1 sensitizes colon cancer cells to DNAPKcs inhibitor KU60648. Mol Carcinog. 2017;56:1816-24.

163. Beebe J, Zhang JT. CC-115, a Dual mammalian target of Rapamycin/DNAdependent protein kinase inhibitor in clinical trial, is a substrate of ATPbinding cassette G2, a risk factOR for CC-115 resistance. J Pharmacol Exp Ther. 2019;371:320-6.

164. Sen T, Tong P, Diao L, Li L, Fan Y, Hoff J, Heymach JV, Wang J, Byers LA Targeting AXL and mTOR pathway overcomes primary and acquired resistance to WEE1 inhibition in small-cell lung cancer. Clin Cancer Res. 2017;23:6239-53.

165. Li F, Guo E, Huang J, Lu F, Yang B, Xiao R, Liu C, Wu X, Fu Y, Wang Z, et al. mTOR inhibition overcomes primary and acquired resistance to Wee1 inhibition by augmenting replication stress in epithelial ovarian cancers. Am J Cancer Res. 2020;10:908-24.

166. Lewis CW, Bukhari AB, Xiao EJ, Choi WS, Smith JD, Homola E, Mackey JR, Campbell SD, Gamper AM, Chan GK. Upregulation of Myt1 promotes acquired resistance of cancer cells to Wee1 inhibition. Cancer Res. 2019;79: 5971-85.

167. Lowery CD, Dowless M, Renschler M, Blosser W, VanWye AB, Stephens JR, Iversen PW, Lin AB, Beckmann RP, Krytska K, et al. Broad spectrum activity of the checkpoint kinase 1 inhibitor prexasertib as a single agent or chemopotentiator across a range of preclinical pediatric tumor models. Clin Cancer Res. 2019;25:2278-89.

168. Blosser WD, Dempsey JA, McNulty AM, Rao X, Ebert PJ, Lowery CD, Iversen PW, Webster YW, Donoho GP, Gong X, et al. A pan-cancer transcriptome analysis identifies replication fork and innate immunity genes as modifiers of response to the CHK1 inhibitor prexasertib. Oncotarget. 2020;11:216-36.

169. Manic G, Signore M, Sistigu A, Russo G, Corradi F, Siteni S, Musella M, Vitale $\mathrm{S}$, De Angelis ML, Pallocca M, et al. CHK1-targeted therapy to deplete DNA replication-stressed, p53-deficient, hyperdiploid colorectal cancer stem cells. Gut. 2018;67:903-17

170. Shalem O, Sanjana NE, Zhang F. High-throughput functional genomics using CRISPR-Cas9. Nat Rev Genet. 2015;16:299-311.

171. Erber J, Steiner JD, Isensee J, Lobbes LA, Toschka A, Beleggia F, Schmitt A, Kaiser RWJ, Siedek F, Persigehl T, et al. Dual inhibition of GLUT1 and the ATR/CHK1 kinase axis displays synergistic cytotoxicity in KRAS-mutant cancer cells. Cancer Res. 2019;79:4855-68. 
172. Wood K, Hensing T, Malik R, Salgia R. Prognostic and predictive value in KRAS in non-small-cell lung cancer: a review. JAMA Oncol. 2016;2:805-12.

173. Goldberg MS. Improving cancer immunotherapy through nanotechnology. Nat Rev Cancer. 2019:19:587-602.

174. Martin JD, Cabral H, Stylianopoulos T, Jain RK. Improving cancer immunotherapy using nanomedicines: progress, opportunities and challenges. Nat Rev Clin Oncol. 2020;17:251-66.

175. Riley RS, June CH, Langer R, Mitchell MJ. Delivery technologies for cancer immunotherapy. Nat Rev Drug Discov. 2019;18:175-96.

176. Du C, Qi Y, Zhang Y, Wang Y, Zhao X, Min H, Han X, Lang J, Qin H, Shi Q, et al. Epidermal growth factor receptor-targeting peptide nanoparticles simultaneously deliver gemcitabine and olaparib to treat pancreatic cancer with breast cancer 2 ( BRCA2) Mutation. ACS Nano. 2018;12:10785-96.

177. Ebeid K, Meng X, Thiel KW, Do AV, Geary SM, Morris AS, Pham EL, Wongrakpanich A, Chhonker YS, Murry DJ, et al. Synthetically lethal nanoparticles for treatment of endometrial cancer. Nat Nanotechnol. 2018; 13:72-81.

178. Rolfo C, Giovannetti E. A synthetic lethal bullet. Nat Nanotechnol. 2018;13:6-7.

179. Zhang D, Baldwin P, Leal AS, Carapellucci S, Sridhar S, Liby KT. A nanoliposome formulation of the PARP inhibitor Talazoparib enhances treatment efficacy and modulates immune cell populations in mammary tumors of BRCA-deficient mice. Theranostics. 2019:9:6224-38.

\section{Publisher's Note}

Springer Nature remains neutral with regard to jurisdictional claims in published maps and institutional affiliations.

Ready to submit your research? Choose BMC and benefit from:

- fast, convenient online submission

- thorough peer review by experienced researchers in your field

- rapid publication on acceptance

- support for research data, including large and complex data types

- gold Open Access which fosters wider collaboration and increased citations

- maximum visibility for your research: over $100 \mathrm{M}$ website views per year

At BMC, research is always in progress.

Learn more biomedcentral.com/submissions 